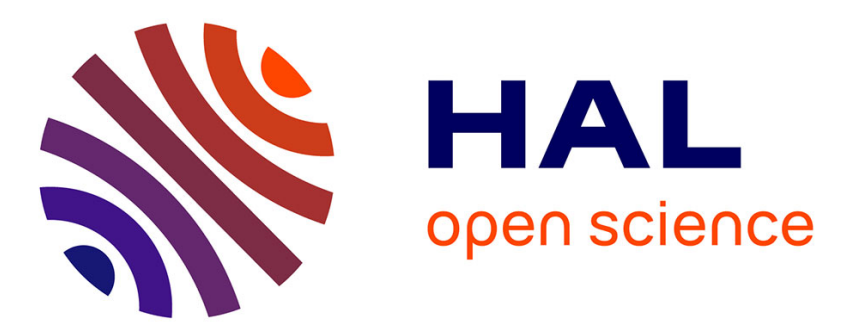

\title{
A Brief Review and Evaluation of Available 1-Dimensional Models for the Borehole Thermal Performance Prediction in a Ground-Coupled Heat Pump System
}

Ali H Tarrad

\section{To cite this version:}

Ali H Tarrad. A Brief Review and Evaluation of Available 1-Dimensional Models for the Borehole Thermal Performance Prediction in a Ground-Coupled Heat Pump System. Current Approaches in Science and Technology Research Vol. 13, pp.145 - 170, 2021, 10.9734/bpi/castr/v13/3282f . hal03328396

\section{HAL Id: hal-03328396 \\ https://hal.science/hal-03328396}

Submitted on 30 Aug 2021

HAL is a multi-disciplinary open access archive for the deposit and dissemination of scientific research documents, whether they are published or not. The documents may come from teaching and research institutions in France or abroad, or from public or private research centers.
L'archive ouverte pluridisciplinaire $\mathbf{H A L}$, est destinée au dépôt et à la diffusion de documents scientifiques de niveau recherche, publiés ou non, émanant des établissements d'enseignement et de recherche français ou étrangers, des laboratoires publics ou privés. 


\title{
A Brief Review and Evaluation of Available 1- Dimensional Models for the Borehole Thermal Performance Prediction in a Ground-Coupled Heat Pump System
}

\author{
Ali H. Tarrad ${ }^{1 *}$ \\ DOI: 10.9734/bpi/castr/v13/3282F
}

\begin{abstract}
The borehole thermal performance prediction is critical in the performance assessment and economical utilization of the ground source heat pump (GSHP). Hence, it is inevitable to evaluate these correlations and reveal their accuracy limits before adapting to the thermal design of the ground heat exchangers. The present article launches an evaluation for the available correlations of the borehole thermal resistance predictions in the direct ground exchange (DX) condenser when it circulates R-410A refrigerant. Eleven elected correlations in the open literature were examined to predict the thermal resistance of vertical single and double U-tube heat exchangers for various geometry configurations. A hypothetical (3.5) kW cooling unit of (3.6) COP was employed to investigate the borehole thermal resistance and depth of the ground copper tubing DX condenser in a single and two-loops design. A large scatter was evident for the borehole thermal resistance and depth as predicted by these correlations. It was as much as double for the examined single and double U-tube geometries. The principal outcome of the present study proved that the utilization of these correlations is only in the preliminary thermal design of the ground source heat pumps (GSHPs). They cannot be adopted for a finalized thermal structure of the borehole without being supported by experimental data due to their predictions' wide range of variations. Many correlations showed good interaction with the borehole configuration, tube diameter $\left(d_{o}\right)$, tube center-center spacing $\left(S_{p}\right)$, and borehole size $\left(D_{B}\right)$. All of the examined models showed that increasing the grout thermal conductivity enhances the thermal performance of the borehole and minimizes the depth for given operating conditions.
\end{abstract}

Keywords: Borehole configuration; thermal resistance correlations; ground-heat exchangers; evaluation; Direct Exchange (DX) Condenser

\section{NOMENCLATURE}

$\begin{array}{ll}D & \text { Tube diameter, } m \\ D & \text { Diameter, } m \\ F & \text { Configuration factor defined in Eq. (23) } \\ h & \text { Convection heat transfer coefficient, } W / m^{2} K \\ H & \text { Depth, } m \\ k & \text { Thermal conductivity, W/m.K } \\ l_{p} & \text { Tube offset length, } m \\ N & \text { Number of loops } \\ q & \text { Heat transfer rate per unit length, W/m } \\ Q & \text { Heat transfer rate } \\ R & \text { Thermal resistance per unit length, } m . K / W\end{array}$


Current Approaches in Science and Technology Research Vol. 13 A Brief Review and Evaluation of Available 1-Dimensional Models for the Borehole Thermal Performance Prediction in a Ground-Coupled Heat Pump System

$\begin{array}{ll}S & \text { Geometry shape factor, } m \\ S_{p} & \text { Shank spacing, } m \\ t & \text { Thickness, } m \\ T & \text { Fluid or wall temperature, } K \\ \Delta T & \text { Temperature difference, } K \\ x & \text { Parameter defined in Eq. (4) } \\ Z & \text { Diagonal center to center spacing, } \mathrm{mm}\end{array}$

\section{Subscribes}

$\begin{array}{ll}a & \text { Tube leg (a) } \\ b & \text { Tube leg (b) } \\ B & \text { Borehole } \\ \text { corr } & \text { Correlation value } \\ e & \text { Equivalent } \\ f & \text { Filling } \\ g & \text { Grout } \\ i & \text { Inside } \\ m & \text { Mean } \\ \text { max } & \text { Maximum } \\ \text { mul } & \text { Multi loops } \\ o & \text { Outside } \\ \text { off } & \text { Offset } \\ p & \text { Pipe } \\ s & \text { A single-loop value } \\ S & \text { Soil or Shank } \\ t & \text { Total } \\ T & \text { Two-loops }\end{array}$

\section{Greek Letters}

a Thermal beams obstruction angle, rad

$\beta \quad$ Equivalency coefficient, Eq. (1)

$\varepsilon \quad$ Ratio defined in Eq. (10)

$\xi \quad$ Augmentation factor defined in Eq. (27)

$\eta \quad$ Deviation percentage defined in Eq. (26)

$\sigma \quad$ Obstruction factor defined in Eqs. $(12,15)$

\section{ABBREVIATIONS}

$\begin{array}{ll}\text { Parameter } & \text { Definition } \\ \text { CF } & \text { Configuration fraction } \\ \text { COP } & \text { Coefficient of performance } \\ D X & \text { Direct contact or exchange } \\ \text { GHE } & \text { Ground heat exchanger } \\ \text { GSHP } & \text { Ground source heat pump } \\ H D P E & \text { High-density Polyethylene } \\ W F & \text { Wall factor, } W F=d_{o} / t\end{array}$

\section{INTRODUCTION}

The modeling of heat transfer in a ground heat exchanger is a complex problem. The ground source heat pump (GSHP) thermal efficiency is mainly controlled among other factors by the ground heat exchanger. The heat transfer process is affected by many variables, such as ground undisturbed temperature, the geological structure of the ground, and the thermal features of grout and soil. 
Current Approaches in Science and Technology Research Vol. 13

Further, the existence of underwater has its impact on the heat transfer process as well. Therefore, a careful design of the ground heat exchanger is a mandatory technical demand in the (GSHP) technology.

Many models for the ground heat exchangers were numerically and analytically investigated in one, two, and three-dimensional representations operate under steady and transient conditions. The transient heat transfer process is the controlling mechanism due to the soil thermal resistance variation with the time of the year, Bauera et al. [1] and Rees and He [2], Chiasson [3], Jalaluddin et al. [4], Zanchini et al. [5], and Zanchini [6]. Quantitative and Qualitative numerical analyses have been conducted to predict the steady-state and time-dependent thermal performance of the single and multiple vertical U-tube borehole heat exchanger [7-13]. A steady-state operating condition is usually considered for modeling the vertical single and multi U-tube configurations, Yavuzturk et al. [14]. Although the soil thermal resistance is a time-dependent factor it has been found that the soil thermal resistance approaches a steady-state condition after only one year of continuous operation of the ground heat exchanger, Garbai and Méhes [15]. The one-dimensional heat transfer process is usually considered for the operation of the ground heat exchangers because the borehole depth is much larger than its diameter. Many correlations are available in the open literature to predict the thermal resistance of the single and double U-tube ground heat exchangers, [16-27].

The present study outlines a brief review of some of the available borehole thermal resistance correlations. A comparison between these models for predicting the borehole heat transfer rate and depth of both single and two-loops for the condensation of the non-azeotropic mixture refrigerant $\mathrm{R}$ 410-A is discussed. Eight models for the single U-tube and three correlations for the double U-tube were implemented for the present work. Two borehole configurations were used for a range of a copper U-tube geometry factor $\left(\mathrm{S}_{\mathrm{p}} / \mathrm{d}_{\mathrm{o}}\right)$ of $(2-4)$ defined as the ratio between the center-center tube spacing divided by the outer diameter of the tube. Quite a good range of practical grout thermal conductivity was utilized in the present investigation, it fell within the scope of $(0.73-1.9) \mathrm{W} / \mathrm{m} . \mathrm{K}$.

\section{INVESTIGATION APPROACH}

The borehole configuration for single and double-loop heat exchangers is illustrated in Fig. 1.

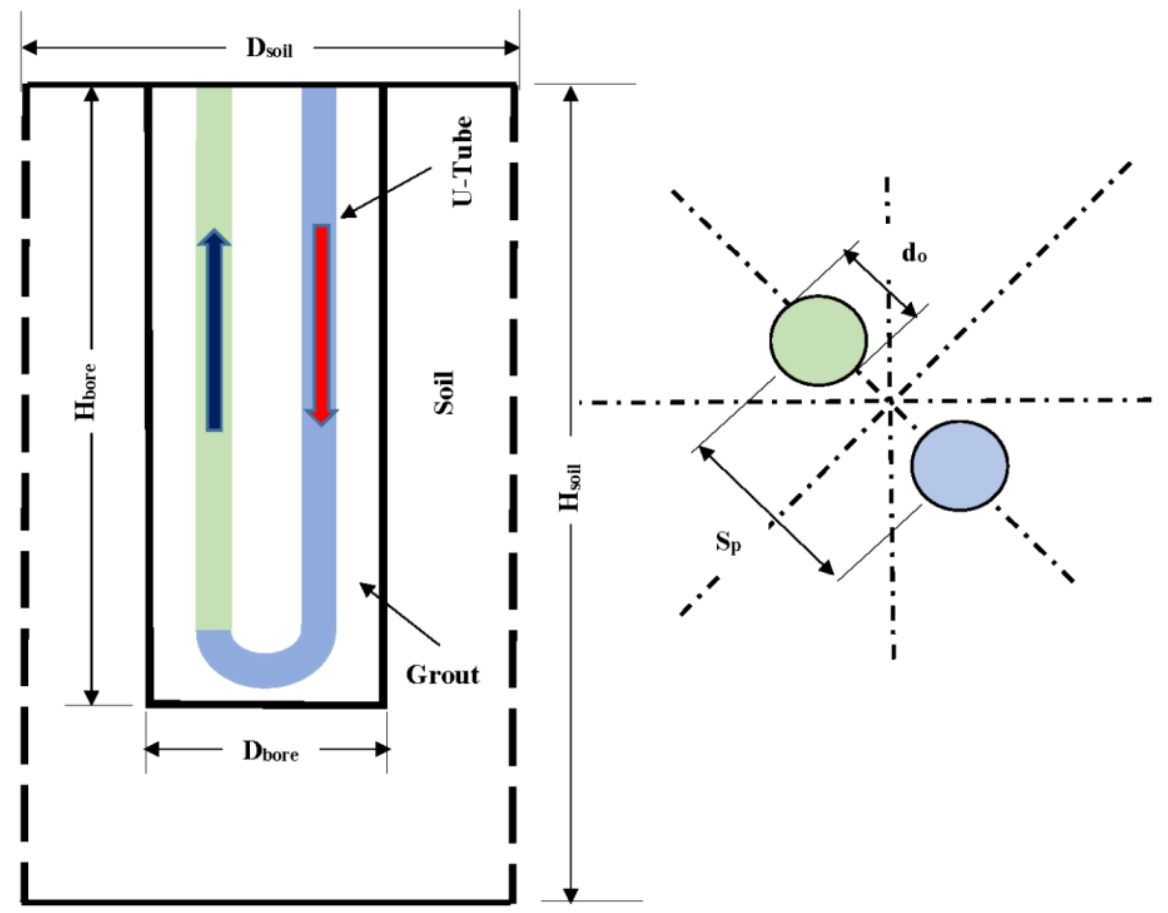

Fig. 1a. A schematic diagram of a single-loop borehole 


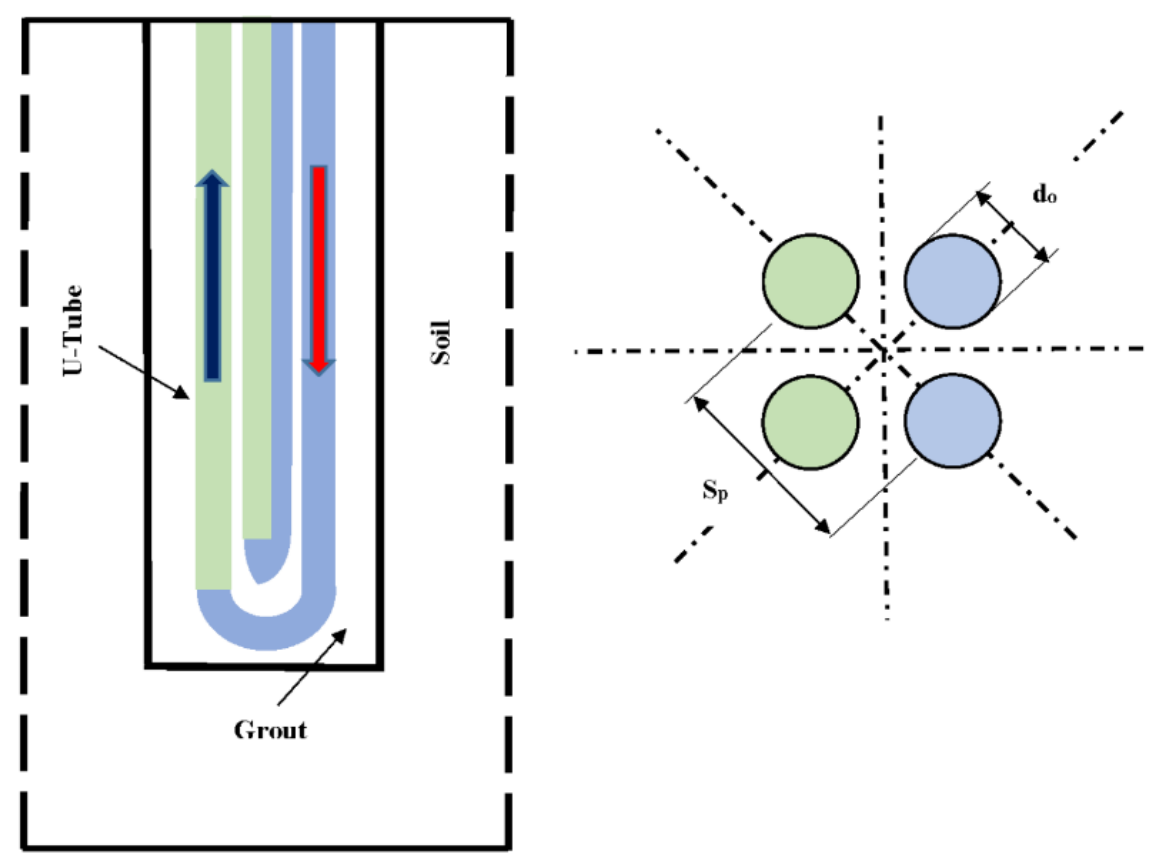

Fig. 1b. A schematic diagram of a double-loop borehole in parallel flow and cross-orientation in situ

Fig. 1. Borehole configurations for single and double-loop layouts, Tarrad [13]

The heat exchanger is composed of a U-tube or double U-tube inserted in the well for specified depth ( $H_{\text {bore }}$ ). The space between these tubes and the borehole wall at ( $D_{\text {bore }}$ ) is usually filled with a conducting material called grout. It is surrounded by the soil that is extended to infinity. The borehole's numerical modeling and design calculations consider a limited thickness of the soil layer of diameter (Dsoil). The double U-tube configuration has many layouts and tube arrangements inside the borehole according to the fluid flow path, parallel or series, and cross or parallel orientation, Tarrad [13].

\section{SINGLE U-TUBE CONFIGURATION}

\subsection{Equivalent Diameter Technique}

Most of the available single U-tube correlations are based on the replacement of the U-tube configuration with an equivalent tube criterion that has a close representation of the original U-tube geometry. The equivalent tube diameter of a U-tube can be presented in the form of:

$$
d_{e}=\beta d_{o}
$$

The equivalency coefficient $(\beta)$ is a constant greater than (1.0). It plays a major role factor in thermal performance assessment. The physical explanation of the $(\beta)$ impact on the thermal performance of the borehole is directly related to the contact surface area of the heat exchanger and the effective volume of the backfill that fills the borehole. Both of these factors are coupled to manifest the heat transfer rate for steady-state and transient thermal performance of the ground heat exchanger (GHE).

Bose et al. [16] modeled the U-tube legs as a single pipe in the center of the bore with an equivalent radius that accounted for the same cross-sectional area of heat exchange. The heat conduction between the thin film, filling material, and ground was calculated in the radial direction in the form:

$$
R_{f=} \frac{\ln \left(\frac{D_{B}}{\sqrt{n} d_{o}}\right)}{2 \pi k_{g}}
$$

Where $(n)$ is equal to (2) for a single U-tube system, hence $(\beta)$ equal to $(\sqrt{2})$. 
The value of $(\beta)$ for two buried horizontal pipes was proposed to be $(\sqrt{2})$ by Claesson and Dunand [20]. They concluded that the value of the coefficient $(\beta)$ must be $(<2)$. Fischer and Stickford [17] indicated that the equivalency coefficient $(\beta)$ corresponds to (1.84). Mei and Baxter [18] stated experimentally that the value of the equivalency coefficient varies from one well to another. It has a scatter between (1.0) and (1.662) with a mean value of (1.28). A one-dimensional heat transfer model was built by Shonder and Beck [21] for the U-tube heat exchanger. They substituted the U-tube legs with an equivalent concentric tube at the borehole. They also arrived at $(\sqrt{2})$ for the equivalency coefficient for a single vertical U-tube ground heat exchanger.

Gu and O'Neal [22] considered a steady-state heat transfer simulation based on the cylindrical source model. They presented the equivalent diameter in a formula that coupled the tube diameter and the leg spacing in the form:

$$
d_{e}=\sqrt{S_{p} d_{o}}
$$

And the borehole thermal resistance presented by Sagia et al. [27] as:

$$
R_{f=} \frac{\ln \left(\frac{D_{B}}{d_{o}} \sqrt{\frac{d_{o}}{S_{p}}}\right)}{2 \pi k_{g}}
$$

Tarrad [24] has reported a simple correlation for the prediction of the filling thermal resistance in a vertical single U-tube ground heat exchanger. It has incorporated the various geometrical parameters in the thermal assessment of the resistance in the expression:

$$
\begin{aligned}
& d_{e}=\frac{D_{B}}{\left(x+\sqrt{x^{2}-1}\right)} \\
& x=\frac{D_{B}{ }^{2}+d_{o}{ }^{2}-S_{p}{ }^{2}}{2 D_{B} d_{o}}
\end{aligned}
$$

The correlation showed an acceptable agreement with previously available ones in the open literature. Tarrad [25] presented a correlation for the borehole thermal resistance based on the equivalent tube diameter technique. He has stated that the equivalent concentric tube has the expression:

$$
d_{e}=\frac{\sqrt{2} d_{o}+2 d_{o}}{2} \approx \sqrt{3} d_{o}
$$

In this expression, the equivalency coefficient $(\beta)$ in Eq. (1) is equal to $(\sqrt{3})$.

Tarrad [25] has also emphasized that the shape of the expression in Eq. (5.a) could be utilized for the case when the U-tube composes of different leg sizes which are the usual geometry considered for condensers and evaporators. The vapor phase passes through a leg of a bigger diameter than that of the liquid phase for hydrodynamic reasons. The following relation still holds in the form of:

$$
d_{e}=\frac{\sqrt{d_{1}^{2}+d_{2}^{2}}+\left(d_{1}+d_{2}\right)}{2}
$$

\subsection{Empirical and Analytical Correlations}

Remund [19] postulated a correlation to predict the borehole thermal resistance for the three configurations of (GHE) pipes, close together, average, and along the outer wall of the borehole in the following expression:

$$
R_{f}=\frac{1}{C_{1} k_{g}\left(\frac{D_{B}}{d_{0}}\right)^{C_{2}}}
$$


Current Approaches in Science and Technology Research Vol. 13 A Brief Review and Evaluation of Available 1-Dimensional Models for the Borehole Thermal Performance Prediction in a Ground-Coupled Heat Pump System

Where the values of the coefficient $\left(C_{1}\right)$ and the index $\left(C_{2}\right)$ were stated for three cases as illustrated in Table 1.

Table 1. Coefficients of equation (6), [19]

\begin{tabular}{lll}
\hline Configuration & $\boldsymbol{C}_{\boldsymbol{1}}$ & $\boldsymbol{C}_{\mathbf{2}}$ \\
\hline Close together & 20.10 & -0.9447 \\
Average & 17.44 & -0.6052 \\
Along outer wall & 21.91 & -0.3796 \\
\hline
\end{tabular}

The shape of the Eq. (6) dictates that for a given borehole configuration, as the tube legs get closer, the borehole thermal resistance showed an increase. It approaches a peak value as the geometry factor $\left(\mathrm{S}_{\mathrm{p}} / \mathrm{d}_{\mathrm{o}}\right)$ is equal to unity; the tube spacing is equal to the U-tube diameter. The minimum value will be experienced as the tube spacing reaches a maximum when the tubes touch the borehole surface.

Garbai and Méhes [15] considered the thermal resistance of filling in a single U-tube in terms of the corresponding thermal resistance of an eccentric pipe as described by Holman [28]. The shape factor of the eccentric tube in a cylindrical geometry is obtained from the relation presented as:

$$
S=\frac{2 \pi L}{\cosh ^{-1}\left\{\frac{D_{B}^{2}+d_{o}^{2}-4 l_{p}^{2}}{2 D_{B} d_{o}}\right\}}
$$

The thermal resistance of the eccentric tube is calculated from:

$$
R_{f}=\frac{1}{S k_{g}}
$$

Sharqawy et al. [29] proposed a numerical model for the steady-state heat conduction within the borehole. They considered various geometries of the U-tube ground heat exchanger and various thermal properties of grout in the simulations. They considered the tube spacing inside the borehole in the correlation formulation. They developed a correlation for the grout thermal resistance as:

$$
R_{f}=\frac{\left(-1.49 \frac{s_{p}}{D_{B}}+0.656 \ln \left(\frac{D_{B}}{d_{o}}\right)+0.436\right)}{2 \pi k_{g}}
$$

Koenig [23] has performed an analytical model for the heat transfer problem in a borehole with single and multi-vertical U-tube loops in thermal resistances layout as shown in Fig. 2.

He postulated a correlation for the borehole thermal resistance of a single U-tube heat exchanger is:

$$
\begin{aligned}
& R_{B}=\frac{\varepsilon R_{p}}{2} \\
& \varepsilon=\frac{R_{f}+R_{p}}{R_{p}} \\
& R_{p}=\frac{1}{\pi d_{i} h}+\frac{\ln \left(\frac{d_{o}}{d_{i}}\right)}{2 \pi k_{p}} \\
& R_{f}=\frac{1}{\sigma} \frac{\cosh ^{-1}\left\{\frac{D_{B}{ }^{2}+d_{o}{ }^{2}-4 l_{p}{ }^{2}}{2 D_{B} d_{o}}\right\}}{2 \pi k_{g}}
\end{aligned}
$$

And the obstruction factor is defined as:

$$
\sigma=1-\frac{q_{3}}{\left(q_{1}+q_{2}\right)}
$$


Current Approaches in Science and Technology Research Vol. 13 A Brief Review and Evaluation of Available 1-Dimensional Models for the Borehole Thermal Performance Prediction in a Ground-Coupled Heat Pump System

Here, the amount of heat shunted between pipes is represented by $\left(q_{3}\right)$. The heat transfer rate from pipe numbers (1) and (2) correspond to $\left(q_{1}\right)$ and $\left(q_{2}\right)$, respectively.

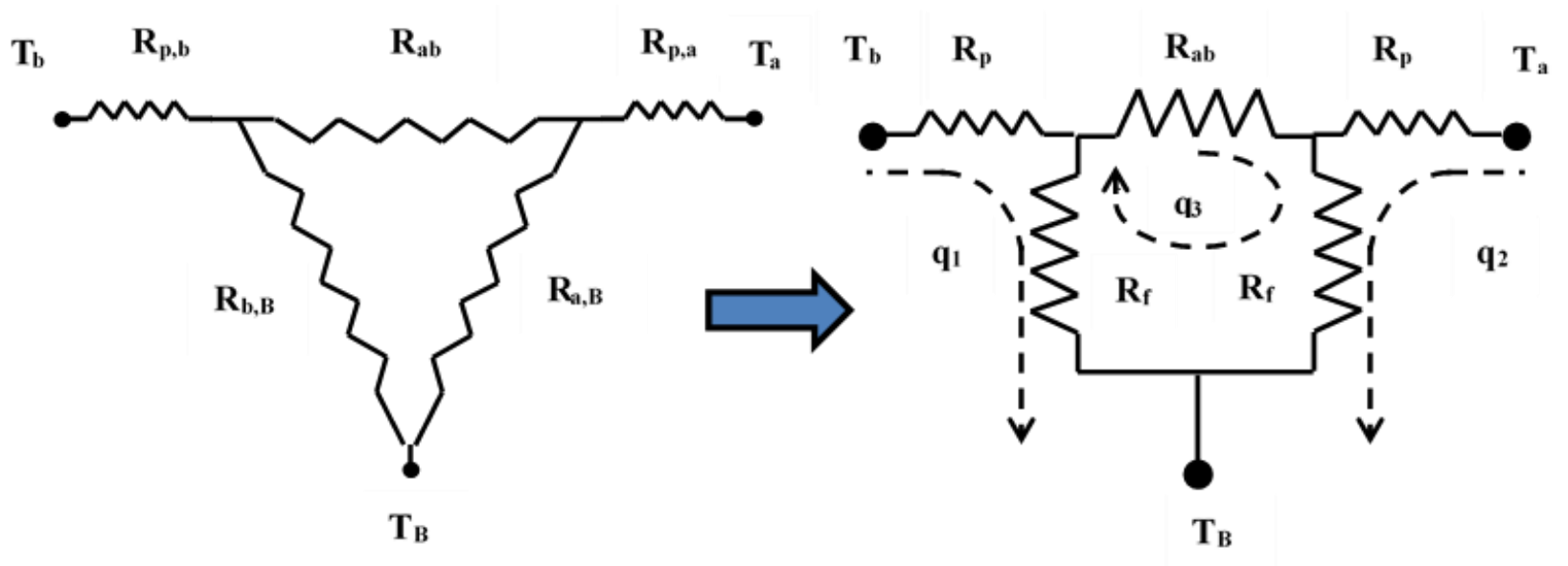

Fig. 2 The thermal circuit presentation for a single U-tube heat exchanger, Koenig [23] and Tarrad [26]

A similar approach was followed by Tarrad [26] to investigate the thermal resistance of the borehole and arrived at an identical expression of Koenig [23] as presented in Eq. (11.a). The obstruction factor to heat transfer is effectively represented by the surface area that is shadowed by the thermal beam of one leg at an angle of $(\alpha)$, Fig. 3.

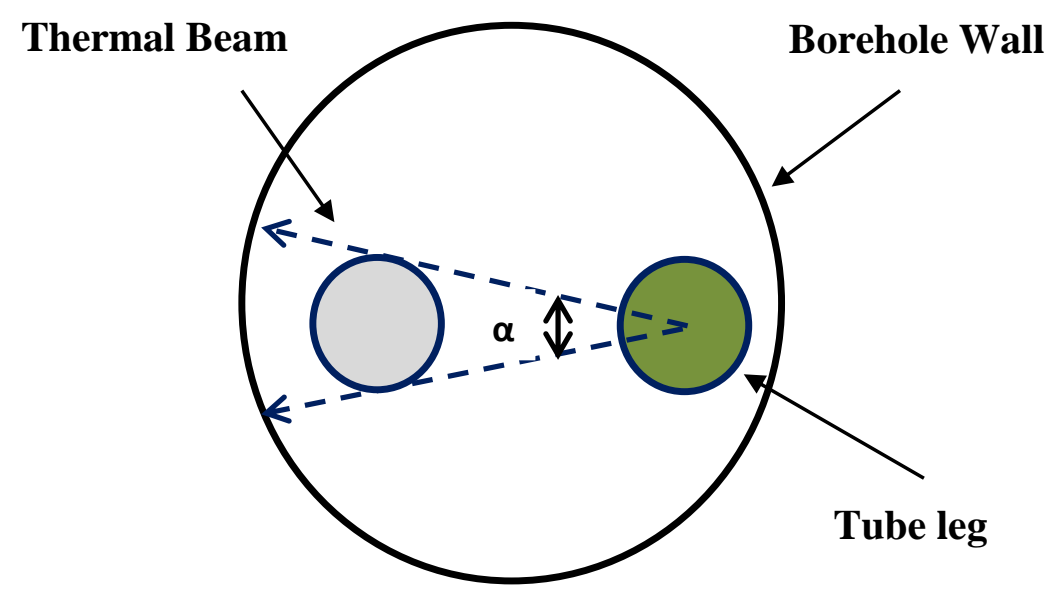

Fig. 3. Thermal representation of the obstruction factor, Tarrad [26]

Here, it is assumed that the heat source, the tube leg represents a line heat transfer source at the center of the tube. The heat transfer mechanism occurs in the radial direction and circumferential heat conduction at the borehole surface is neglected. The latter assumption implicitly states an isothermal condition at the borehole surface. He expressed the obstruction factor to heat transfer in the borehole as a function of the U-tube geometry configuration as:

$$
\sigma=1-\frac{2\left(D_{B}+S_{p}\right) \tan ^{-1}\left(\frac{d_{o}}{2 \sqrt{S_{p}{ }^{2}-\left(\frac{d_{o}}{2}\right)^{2}}}\right)}{\pi D_{B}}
$$

The obstruction factor value lies in the range of $(0<\sigma \leq 1)$. It is equal to unity when there is no obstruction object. Its value is a geometrical parameter depending on the borehole configuration. 
Current Approaches in Science and Technology Research Vol. 13 A Brief Review and Evaluation of Available 1-Dimensional Models for the Borehole Thermal Performance Prediction in a Ground-Coupled Heat Pump System

The borehole thermal resistance may be estimated from the algebraic summation of the pipe thermal resistance Eq. (10.c) and the filling resistance as:

$$
R_{B}=R_{f}+R_{p}
$$

The expression of the borehole thermal resistance as shown in Eq. (13) is valid for all of the examined correlations except those of Koenig [23] and Tarrad [26]. The latter two correlations are already included the filling and pipe thermal resistances in their derivatives.

\section{DOUBLE U-TUBE CONFIGURATION}

There is a quite limited number of thermal resistance prediction correlations for the double U-tube borehole configuration in the open literature. The complicity arises from the fact that there is a mutual heat transfer interaction between the pipes and more obstruction and interference of different pipes for the heat flow between the heat exchanger and surrounding filling material. This factor will be more pronounced for the utilization of a single-phase cooling medium such as water or brines due to the existence of a temperature difference between these tubes. This phenomenon vanishes for condensing a non-azeotropic mixture with a small temperature glide such as R-410A, azeotropic mixture, and pure fluids because the condensation process usually occurs in an isothermal path or close to the isothermal process for these fluids.

\subsection{Tarrad Formula [21]}

More recently, Tarrad [30] developed a correlation for the prediction of the grout thermal resistance of a double U-tube that operates under a steady-state condition. His model was based on the equivalent tube theory and including the obstruction factor due to the existence of other tubes in the heat transfer path as explained in Tarrad [26]. The schematic representation of the model for a double U-tube heat exchanger is shown in Fig. 4.

The final mathematical expression shape is identical to that of the single U-tube one but with the equivalent configuration as shown in Fig. 4, hence:

$$
\begin{aligned}
& d_{e}=\sqrt{2} d_{o} \\
& l_{p, e} \approx l_{p}+0.207 d_{o} \\
& R_{B, e}=\frac{\varepsilon_{e} R_{p}}{2 \sigma} \\
& (14 . \mathrm{C}) \\
& \varepsilon_{e}=\frac{R_{f, e}+R_{p}}{R_{p}} \\
& \left.R_{f, e}=\frac{1}{\sigma} \frac{\cosh ^{-1}\left\{\frac{D_{B}{ }^{2}+d_{e}{ }^{2}-4 l_{p, e}}{2 D_{B} d_{e}}\right\}}{2 \pi k_{g}}\right\}
\end{aligned}
$$




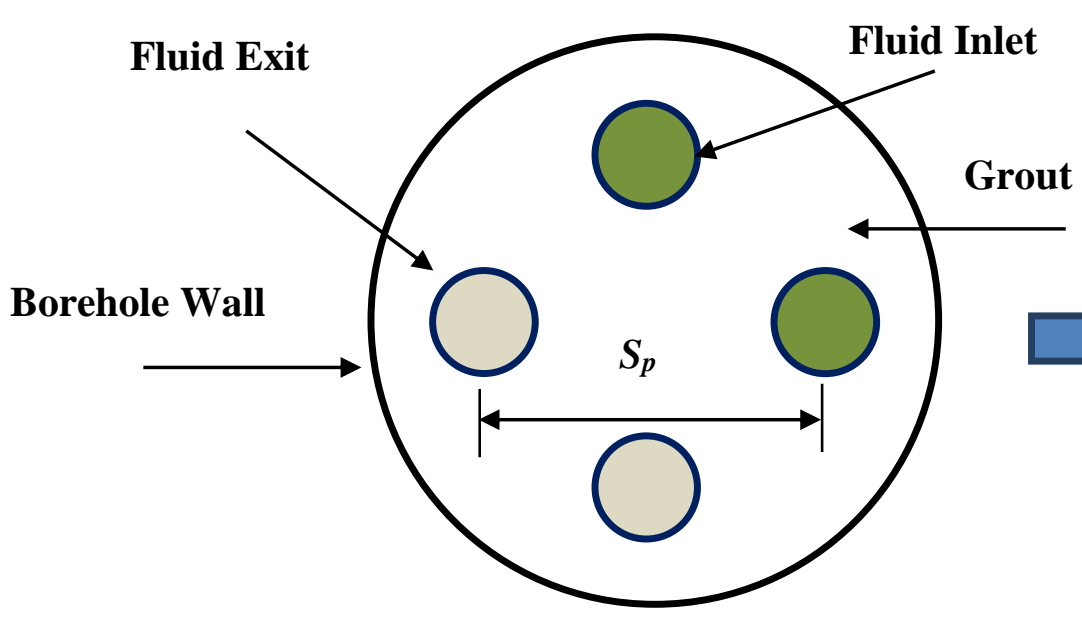

(a) A vertical two U-tube borehole

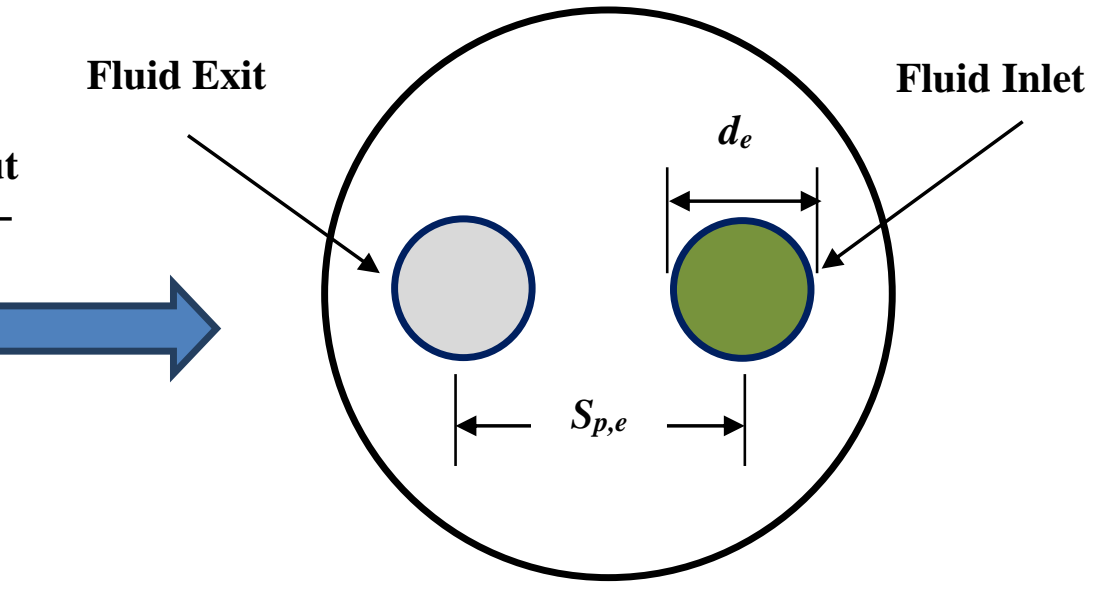

(b) Equivalent system of borehole

Fig. 4. A schematic diagram for the transformation of the double U-tube to an equivalent system, Tarrad [30] 
Current Approaches in Science and Technology Research Vol. 13 A Brief Review and Evaluation of Available 1-Dimensional Models for the Borehole Thermal Performance Prediction in a Ground-Coupled Heat Pump System

The obstruction factor was obtained from Tarrad [26] for the equivalent single loop as:

$$
\sigma=1-\frac{2\left(D_{B}+S_{p, e}\right) \tan ^{-1}\left(\frac{d_{e}}{2 \sqrt{S_{p, e^{2}-\left(\frac{d_{e}}{2}\right)^{2}}}}\right)}{\pi D_{B}}
$$

\subsection{Koenig Formula [23]}

Koenig [23] analyzed the heat transfer problem in a borehole with multi-vertical U-tube loops. He has postulated a correlation for the borehole thermal resistance as follows:

$$
R_{B, m u l}=\sum_{i=1}^{N}\left[R_{B, i} C F_{i}\right] / N
$$

Where $\left(R_{B}\right)$ is the borehole resistance for a single configuration, $(N)$ corresponds to the number of $U$ tube loops situated in the borehole, and $(C F)$ is the configuration fraction. It was prepared for several loops (1-4) in terms of the shank spacing of the U-tube, Table 2 and Fig. 5. The parameter (Z) is the fixed diagonal center to center spacing.

Table 2. Multi-loop pipe-pipe spacing for shunt analysis, Koenig [23]

\begin{tabular}{llll}
\hline No. loops & $\mathbf{S p}$ & $\begin{array}{l}\text { Configuration } \\
\text { occurrences }\end{array}$ & $\begin{array}{l}\text { Configuration fraction } \\
\text { (CF) }\end{array}$ \\
\hline 1 & $\mathrm{Z}$ & 1 & 1 \\
2 & $\mathrm{Z}$ & 2 & $1 / 2$ \\
& $\mathrm{Z} / \sqrt{2}$ & 2 & $1 / 2$ \\
3 & $\mathrm{Z}$ & 3 & $1 / 3$ \\
& $0.866 \mathrm{Z}$ & 4 & $4 / 9$ \\
& $\mathrm{Z} / 2$ & 2 & $2 / 9$ \\
4 & $\mathrm{Z}$ & 4 & $1 / 4$ \\
& $0.9239 \mathrm{Z}$ & 6 & $3 / 8$ \\
& $0.707 \mathrm{Z}$ & 4 & $1 / 4$ \\
& $0.3827 \mathrm{Z}$ & 2 & $1 / 8$ \\
\hline
\end{tabular}
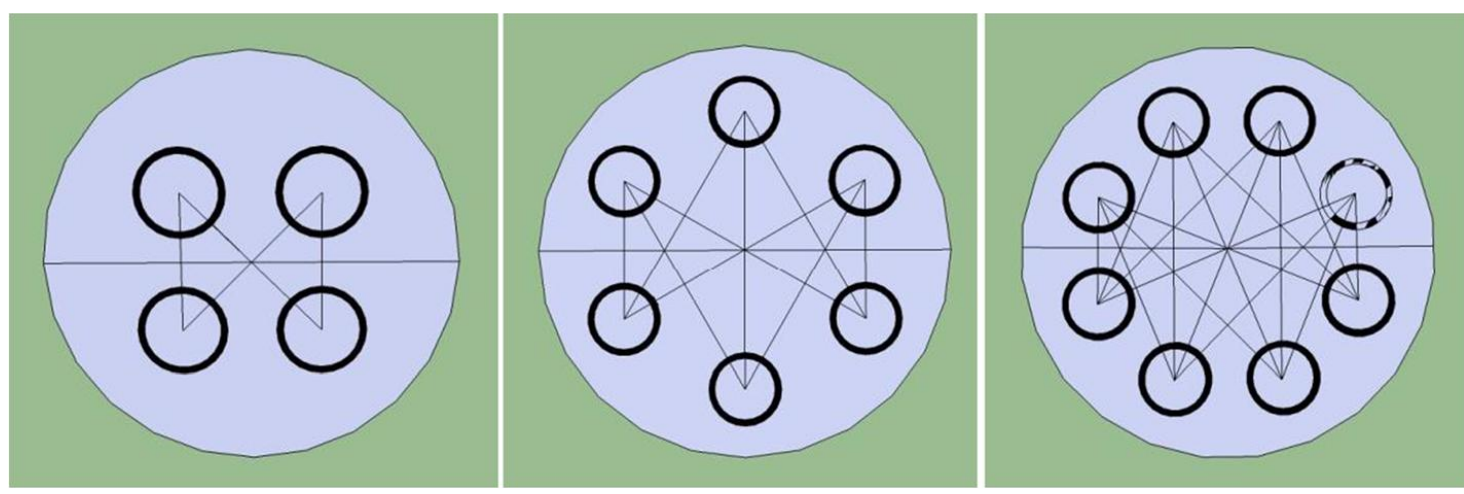

Fig. 5. Compilation of thermal separations between pipes for two-, three-, and four-loop assemblies, Koenig [23]

\subsection{Shonder and Beck Correlation [21]}

Shonder and Beck [21] derived a correlation for the double U-tube configuration similar to that of the single U-tube. It was represented in terms of equivalent tube diameter of the form of Eq. (1); hence the thermal resistance of filling has the form: 
Current Approaches in Science and Technology Research Vol. 13 A Brief Review and Evaluation of Available 1-Dimensional Models for the Borehole Thermal Performance Prediction in a Ground-Coupled Heat Pump System

$$
R_{f}=\frac{\ln \left(\frac{D_{B}}{2 d_{o}}\right)}{2 \pi k_{g}}
$$

This expression dictates that the volume of the grout remains constant for both of the original and equivalent configurations as shown in the following expression:

$$
\frac{\pi}{4}\left(D_{B}^{2}-4 d_{o}^{2}\right) H=\frac{\pi}{4}\left(D_{B}^{2}-d_{e}{ }^{2}\right) H
$$

This relation yields to:

$$
d_{e}=2 d_{o}
$$

Therefore, the equivalency coefficient $(\beta)$ equals (2).

\section{BOREHOLE CONFIGURATION CASE STUDY}

\subsection{Borehole Configuration}

Table 3 illustrates the geometry configuration for a range of tube diameter, borehole size, and U-tube spacings. These configurations are examined with a variety of single U-tube and double U-tube correlations to detect the sensitivity of each of them to the geometry design variation.

Table 3. Selected geometrical configurations for a single U-tube loop

\begin{tabular}{llllll}
\hline Geometry & $\begin{array}{l}\mathbf{d}_{\mathbf{o}} \\
(\mathbf{m m})\end{array}$ & $\begin{array}{l}\mathbf{D}_{\mathbf{B}} \\
(\mathbf{m m})\end{array}$ & $\begin{array}{l}\mathbf{S}_{\mathbf{p}} / \mathbf{d}_{\mathbf{o}} \\
(---)\end{array}$ & $\begin{array}{l}\mathbf{S}_{\mathbf{p}} / \mathbf{D}_{\mathbf{B}} \\
(---)\end{array}$ & $\begin{array}{l}\text { WF } \\
(---)\end{array}$ \\
\hline G1 & 9.525 & 65 & $2-4$ & $0.29-0.59$ & 12.5 \\
G2 & 12.7 & 75 & $2-4$ & $0.34-0.68$ & 14.29 \\
\hline
\end{tabular}

The following assumptions and operating conditions were implemented for the evaluation purposes:

1- Table 4 depicts the grout thermal conductivity in the range of $(0.73-1.9) \mathrm{W} / \mathrm{m} . \mathrm{K}$, Gaia [31].

Table 4. Grout thermal conductivity, [31]

\begin{tabular}{ll}
\hline Grouts & $\mathbf{k}_{\mathbf{g}}(\mathbf{W} / \mathbf{m ~ K})$ \\
\hline $20 \%$ Bentonite & 0.73 \\
$30 \%$ Bentonite & 0.74 \\
Cement Mortar & 0.78 \\
Concrete $2100 \mathrm{~kg} / \mathrm{m}^{3}$ & 1.04 \\
$30 \%$ Bentonite $-30 \%$ Quartzite & 1.3 \\
$30 \%$ Bentonite $-40 \%$ Quartzite & 1.47 \\
$60 \%$ Quartzite- Flowable Fill & 1.85 \\
Concrete (50\% Quartz Sand) & 1.9 \\
\hline
\end{tabular}

2- R-410A is circulated through the heat pump in the DX system. It has a typical condensation heat transfer coefficient of (3000) W/m² K, Huang et al. [32] and Kim and Shin [33].

3- Copper U-tubes are utilized for the ground heat exchanger, the condenser of the heat pump unit. A value of $(400) \mathrm{W} / \mathrm{m} . \mathrm{K}$ was used as the thermal conductivity of the copper tubes.

4- The isothermal condensation process takes place inside the heat exchanger, hence there is no load to be shunted in between the tubes in the borehole geometry.

5- Rejected load to the ground by the copper tubing of the condenser was estimated in the range of (4.4) kW with COP of (3.57) for (3.5) kW cooling unit, Tarrad [26].

6- Absence of underground water flow, hence there is no convection term to be included for the estimation of total borehole thermal resistance. 
7- Perfect contact between the U-tube surface and filling material, hence there is no thermal contact resistance between the surfaces.

\subsection{U-Tube Spacing Limitation}

The constraint of the U-tubes outer circle diameter for practical applications of the ground heat exchanger is controlled by the relation expressed by Koenig [23] and utilized by Tarrad [26,30] in his models as:

$$
D_{S}+2 d_{o} \leq 0.75 D_{B}
$$

Rearranging this relation in terms of the tube spacing $\left(S_{p}\right)$ gives:

$$
S_{p}+d_{o} \leq 0.75 D_{B}
$$

Hence, the maximum practical tube spacing inside the borehole is controlled by:

$$
S_{p, \max }=0.75 D_{B}-d_{o}
$$

The extreme cases where the tubes are touching the borehole wall or touching each other are considered impractical configurations and will not be considered in the present study.

\section{RESULTS AND DISCUSSION}

\subsection{Single Loop Heat Exchanger}

The single loop borehole-specific thermal resistance for the two geometry configurations is compared for (8) available correlations in Figs. 6 and 7.

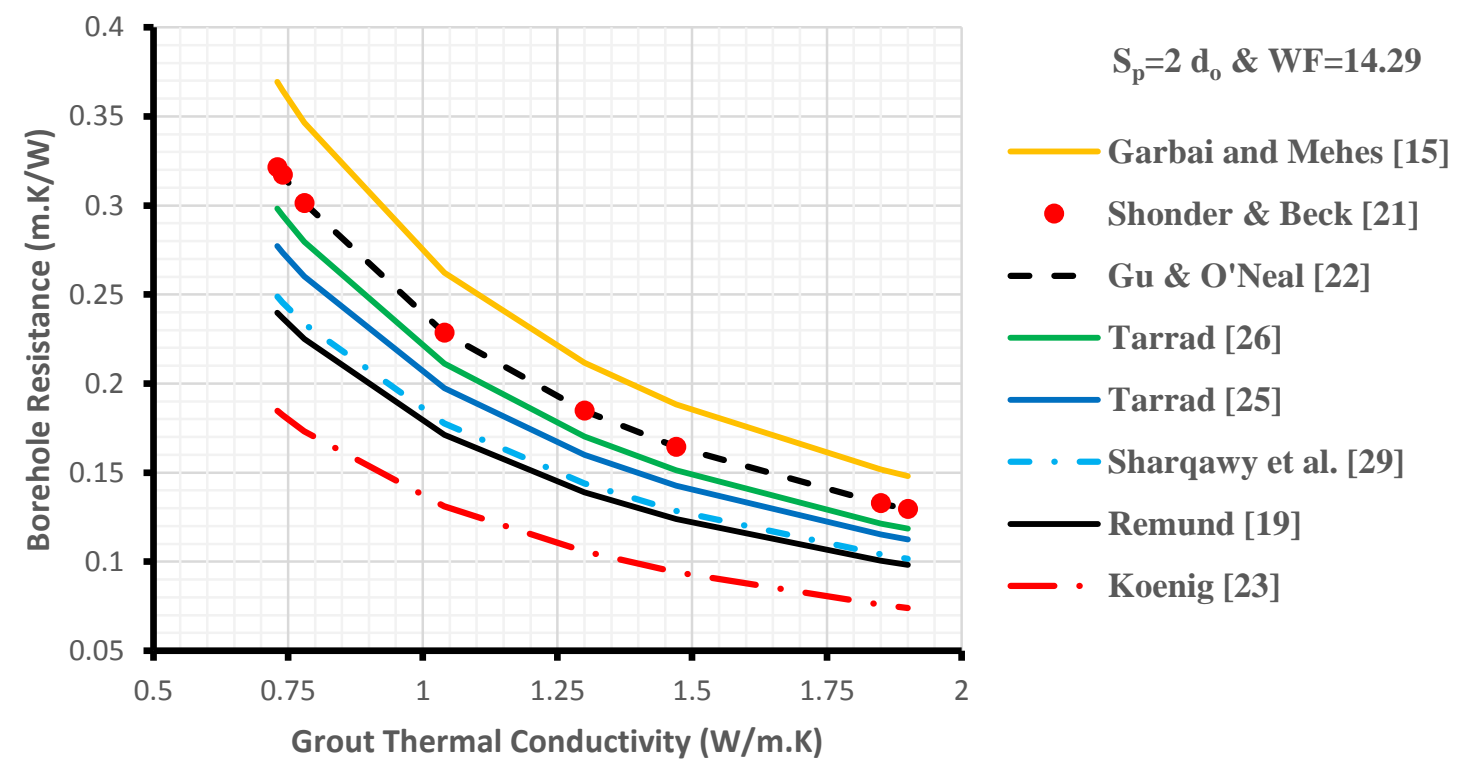

Fig. 6.a. Borehole resistance at WF=14.29, $G 2$ for $S_{p} / d_{0}=2$ 
Current Approaches in Science and Technology Research Vol. 13 A Brief Review and Evaluation of Available 1-Dimensional Models for the Borehole Thermal Performance Prediction in a Ground-Coupled Heat Pump System

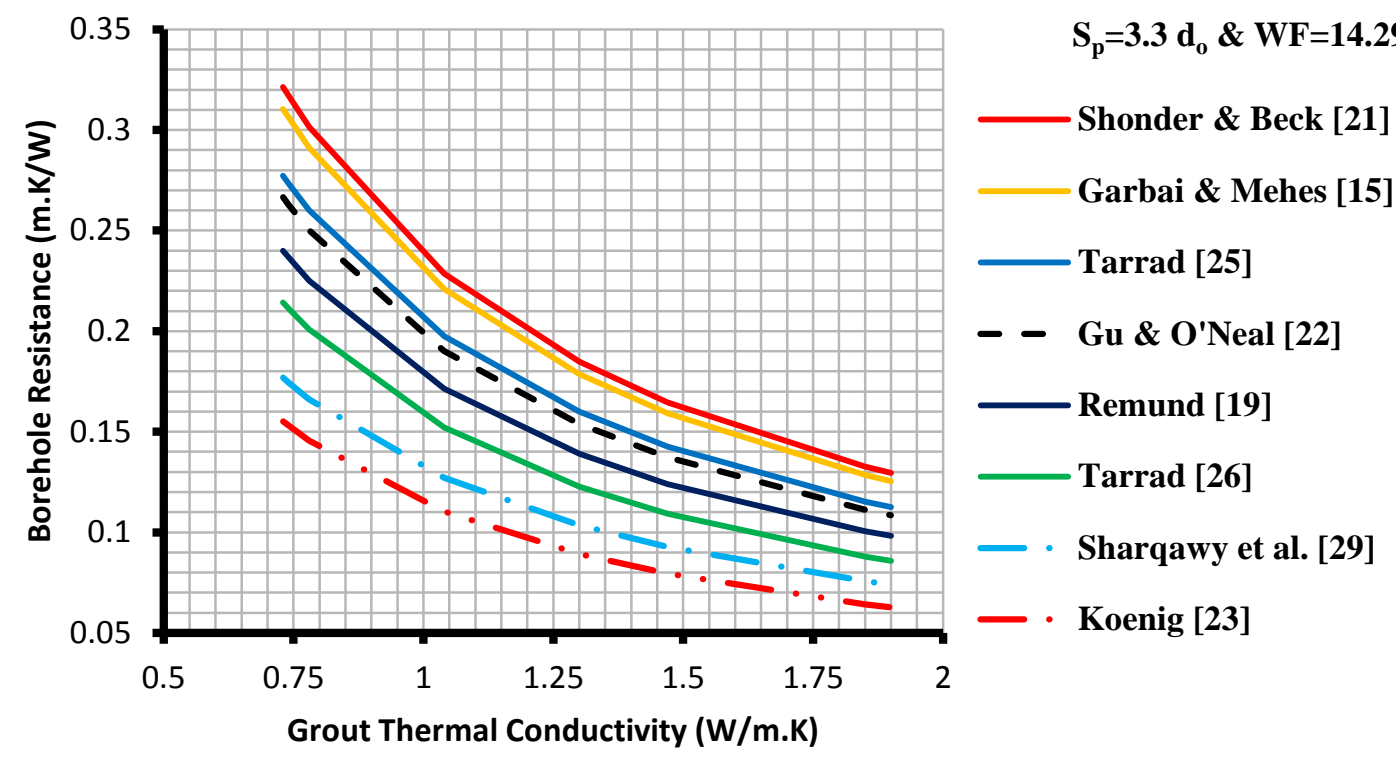

Fig. 6.b. Borehole resistance at $W F=14.29, G 2$ for $S_{p} / d_{0}=3.3$

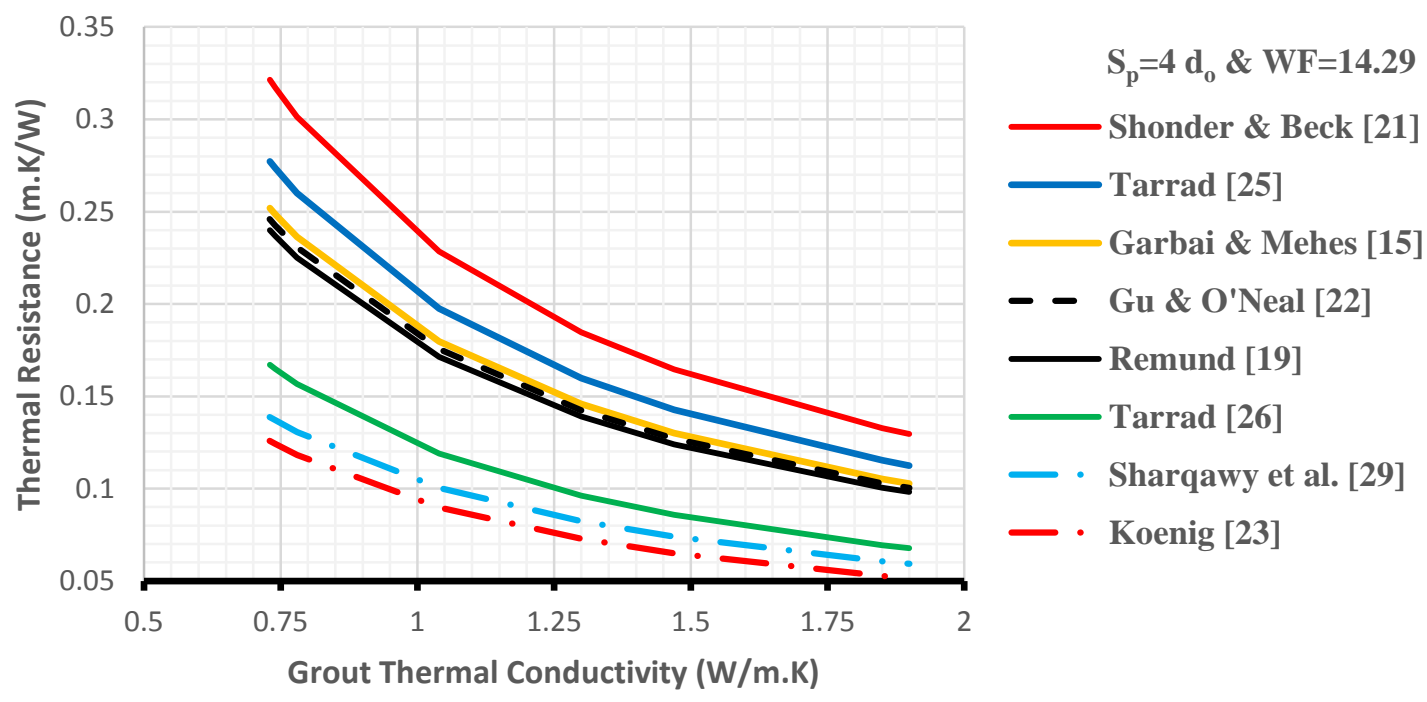

Fig. 6.c. Borehole resistance at WF=14.29, G2 for $S_{p} / d_{0}=4$

Fig. 6. Comparison of the single loop borehole thermal resistance expressions for G2 configuration at a variety of the geometry factor

The correlations of Shonder and Beck [21], Tarrad [25], and Remund [19] predicted the thermal resistance independently of the U-tube spacing. Hence, they produced constant values regardless of the geometry factor for each borehole configuration. For each of the other correlations, the predictions of the borehole thermal resistance dictate that the latter decreases as the geometry factor $\left(S_{p} / d_{0}\right)$ increases and approaching a minimum value at the maximum examined geometry factor of (4). A typical comparison for (G2) showed that at grout thermal conductivity of (1.3) W/m.K, the values at $\left(\mathrm{S}_{\mathrm{p}} / \mathrm{d}_{\mathrm{o}}\right)$ of $(2)$ were $(31) \%,(40) \%$, and $(43) \%$ higher than those at $\left(\mathrm{S}_{\mathrm{p}} / \mathrm{d}_{\mathrm{o}}\right)$ of $(4)$ as predicted by Garbai and Méhes [15], Tarrad [26], and Sharqawy et al. [29], respectively. Similarly, for the (G1) geometry, the respective values at $\left(S_{p} / d_{0}\right)$ of $(2)$ were $(18) \%,(32) \%$, and (32) \% higher than those at 
$\left(S_{p} / d_{0}\right)$ of (4) as predicted by Garbai and Méhes [15], Tarrad [26], and Sharqawy et al. [29] correlations, respectively. These values of increase of the thermal resistances do not show a significant dependence on the grout thermal conductivity.

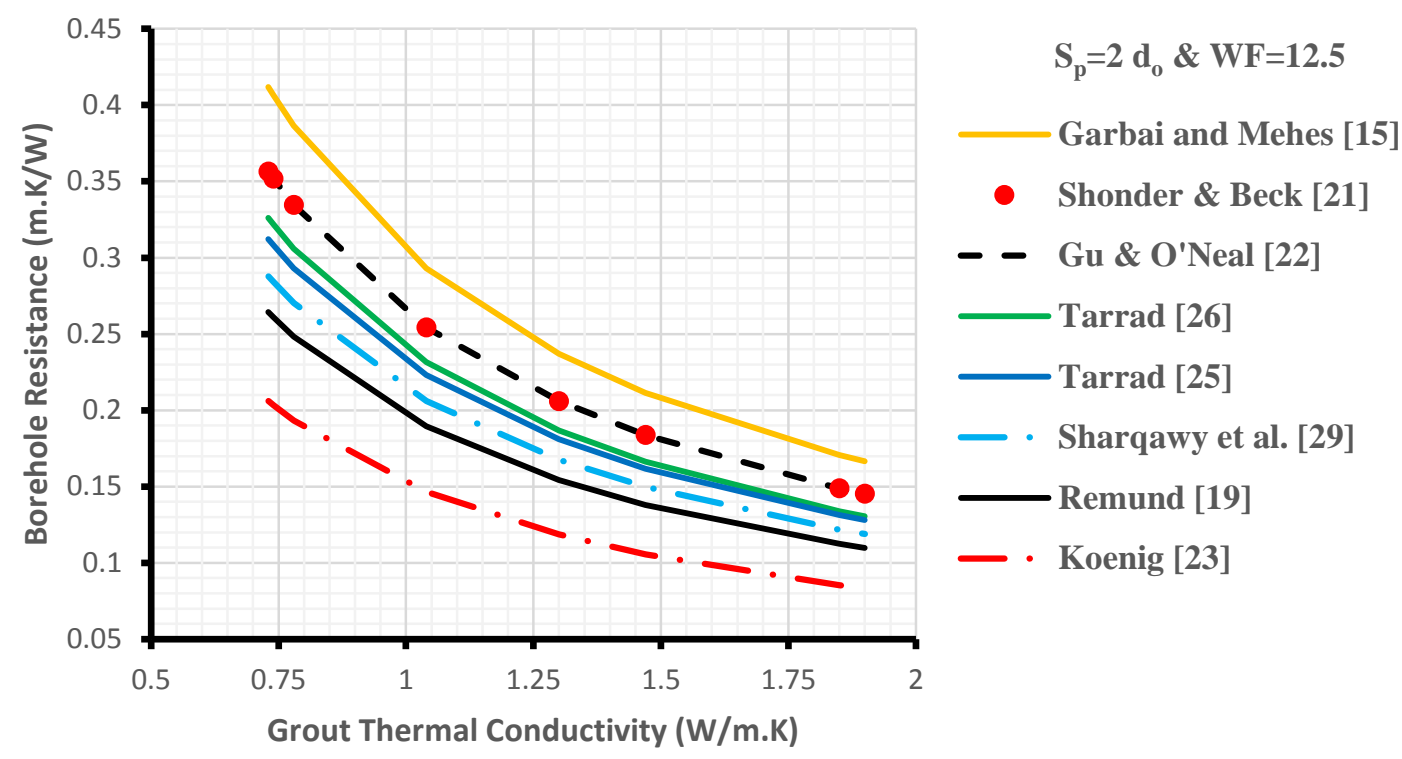

Fig. 7.a. Borehole resistance at $W F=12.5, G 1$ for $S_{p} / d_{0}=2$

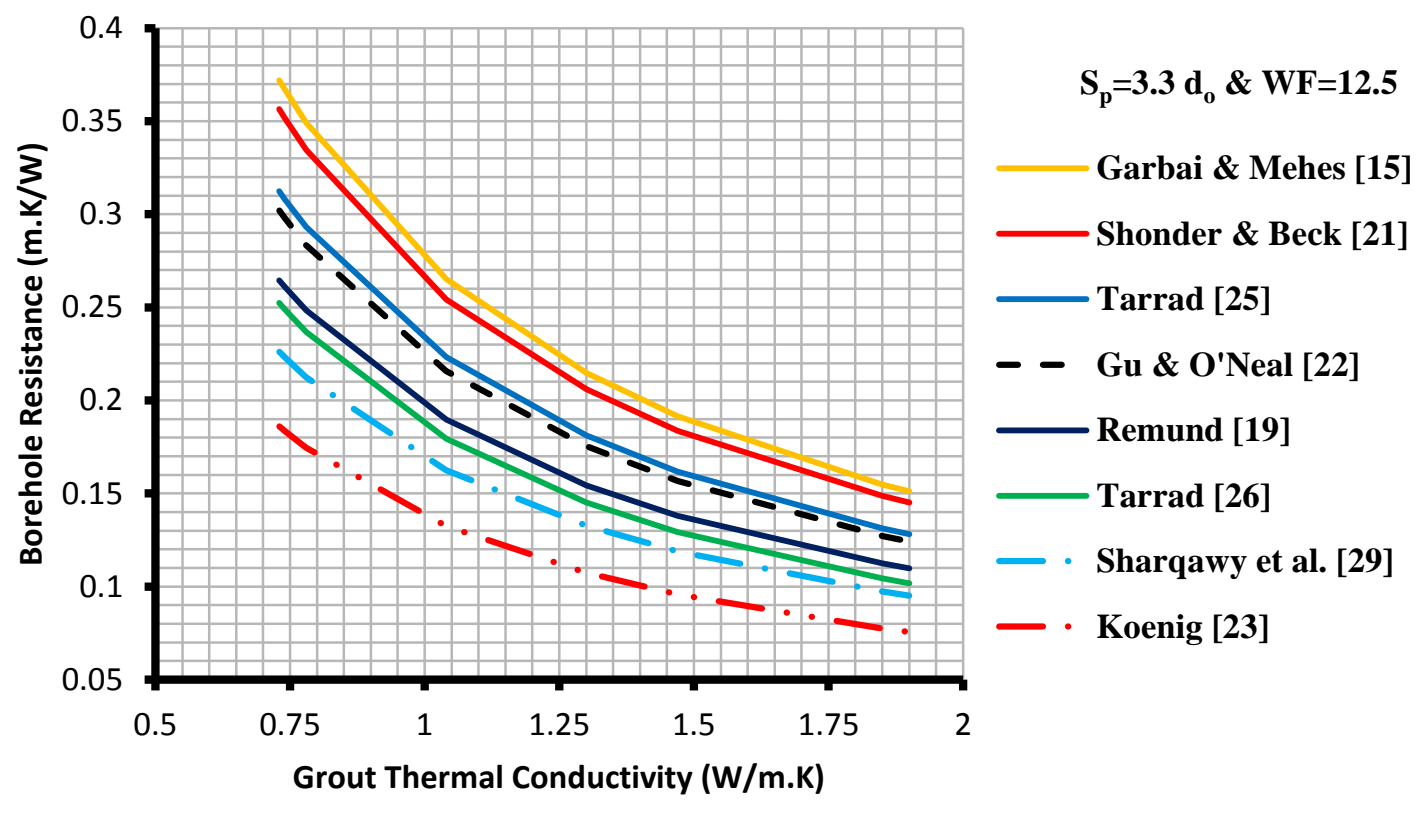

Fig. 7.b. Borehole resistance at $W F=12.5, G 1$ for $S_{p} / d_{0}=3.3$ 


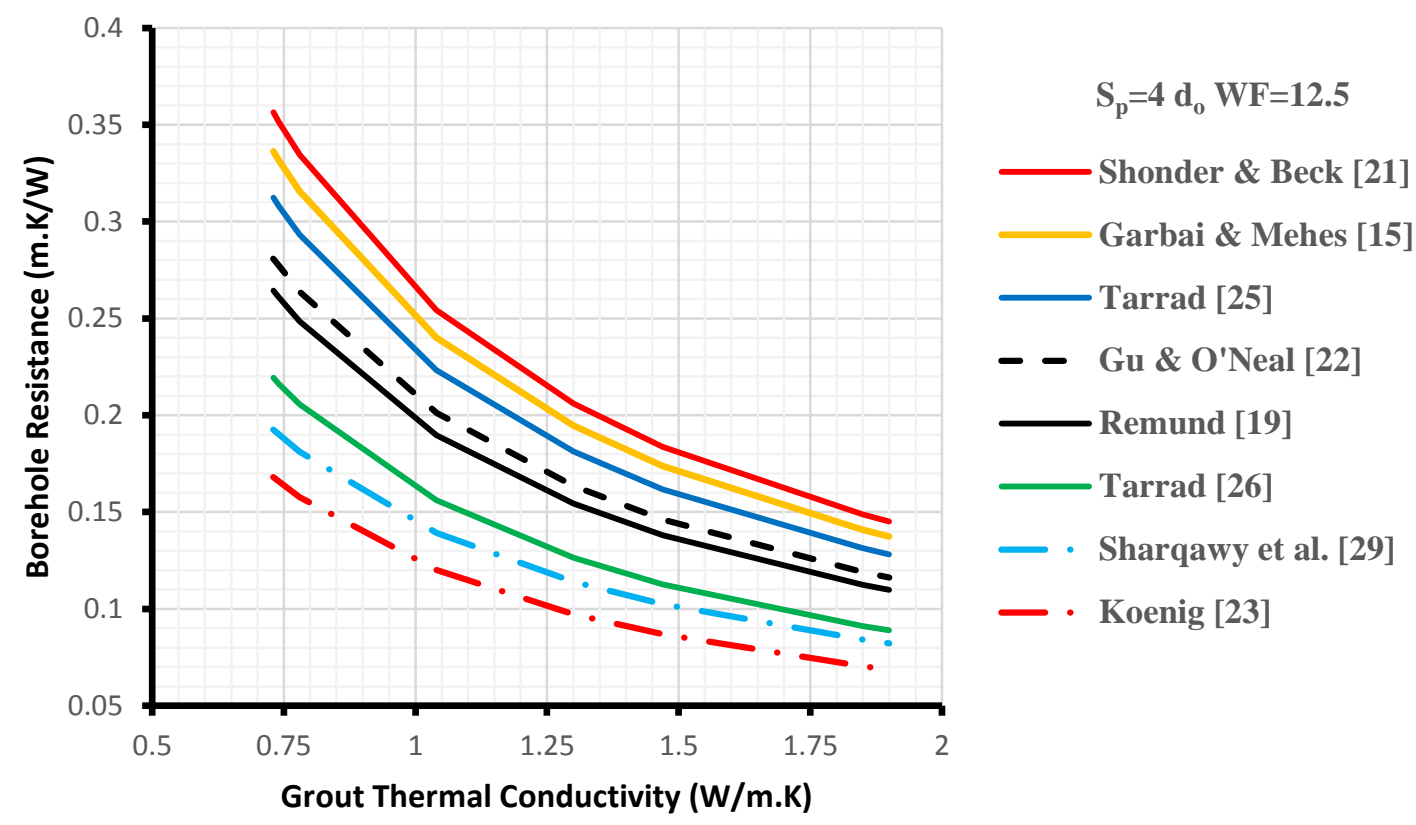

Fig. 7.c. Borehole resistance at WF=12.5, $G 1$ for $S_{p} / d_{0}=4$

Fig. 7. Comparison of the single loop borehole thermal resistance expressions for G1 configuration at a variety of the geometry factors

All correlations exhibited a similar fashion with grout thermal conductivity, the borehole thermal resistance decreases as the grout thermal conductivity increases and vice versa. The predicted borehole thermal resistance by various correlations is getting closer to each other as the grout thermal conductivity increases. The results of the examined correlations exhibited a range of the borehole thermal resistance between $(0.16-0.32) \mathrm{m} .{ }^{\circ} \mathrm{C} / \mathrm{W}$ and $(0.065-0.13) \mathrm{m} .{ }^{\circ} \mathrm{C} / \mathrm{W}$ predicted at $(0.73) \mathrm{W} / \mathrm{m} . \mathrm{K}$ and (1.9) W/m.K, respectively for the WF of (14.29) and $\left(\mathrm{S}_{\mathrm{p}} / \mathrm{d}_{0}\right)$ of (3.3). The corresponding values fell in the range (0.19-0.36) m. ${ }^{\circ} \mathrm{C} / \mathrm{W}$ and $(0.08-0.15) \mathrm{m} .{ }^{\circ} \mathrm{C} / \mathrm{W}$ estimated at $(0.73) \mathrm{W} / \mathrm{m} . \mathrm{K}$ and $(1.9) \mathrm{W} / \mathrm{m} . \mathrm{K}$, respectively for the WF of (12.5) configuration. For each range, the minimum was predicted by Koenig [23] correlation and the maximum was estimated by either Shonder and Beck [21] or Garbai and Méhes [15]. These correlations showed a great discrepancy for their predictions of the borehole thermal resistance as much as double for the whole examined range of operating conditions and configurations. Hence, it is difficult to select the proper correlation for the design purposes unless some experimental data support it.

More recently, Tarrad [13] has examined many published correlations in the open literature to predict the single U-tube borehole thermal resistance and compared them to 3-dimensional model results. $\mathrm{He}$ compared the total borehole thermal resistance as indicated by the correlations built by [16,20-22], and [24-25]. The model was built with the COMSOL Multiphysics 5.4 software for a single high-density polyethylene pipe (HDPE) of (33.4) $\mathrm{mm}$ outside diameter, (66.8) $\mathrm{mm}$ tube spacing, (120) $\mathrm{mm}$ borehole diameter, and (35.1) $\mathrm{m}$ depth. This heat exchanger was utilized to cool down water used to condense the refrigerant in the condenser of a heat pump unit. The correlations predicted a higher total thermal resistance than that of the 3-dimensional model. Although, the results revealed that the correlation built by Tarrad [25] as stated in Eq. (5) predicted a close value to that of the 3-dimensional model simulation, it was higher by only (5) \% than that of the numerical prediction. It was followed by the predictions of Tarrad [24] and Gu and O'Neal [22] with deviations of (13) \% and (16) \%, respectively. Finally, the higher deviation of the thermal resistance prediction was obtained with Bose et al. (1985) [16], Claesson and Dunand [20], and Shonder and Beck [21] with an (18) \%. 
Current Approaches in Science and Technology Research Vol. 13 A Brief Review and Evaluation of Available 1-Dimensional Models for the Borehole Thermal Performance Prediction in a Ground-Coupled Heat Pump System

\subsection{Double U-Tube Heat Exchanger}

The available correlations for the prediction of the borehole thermal resistance at two values of geometry factors are compared in Fig. 8.

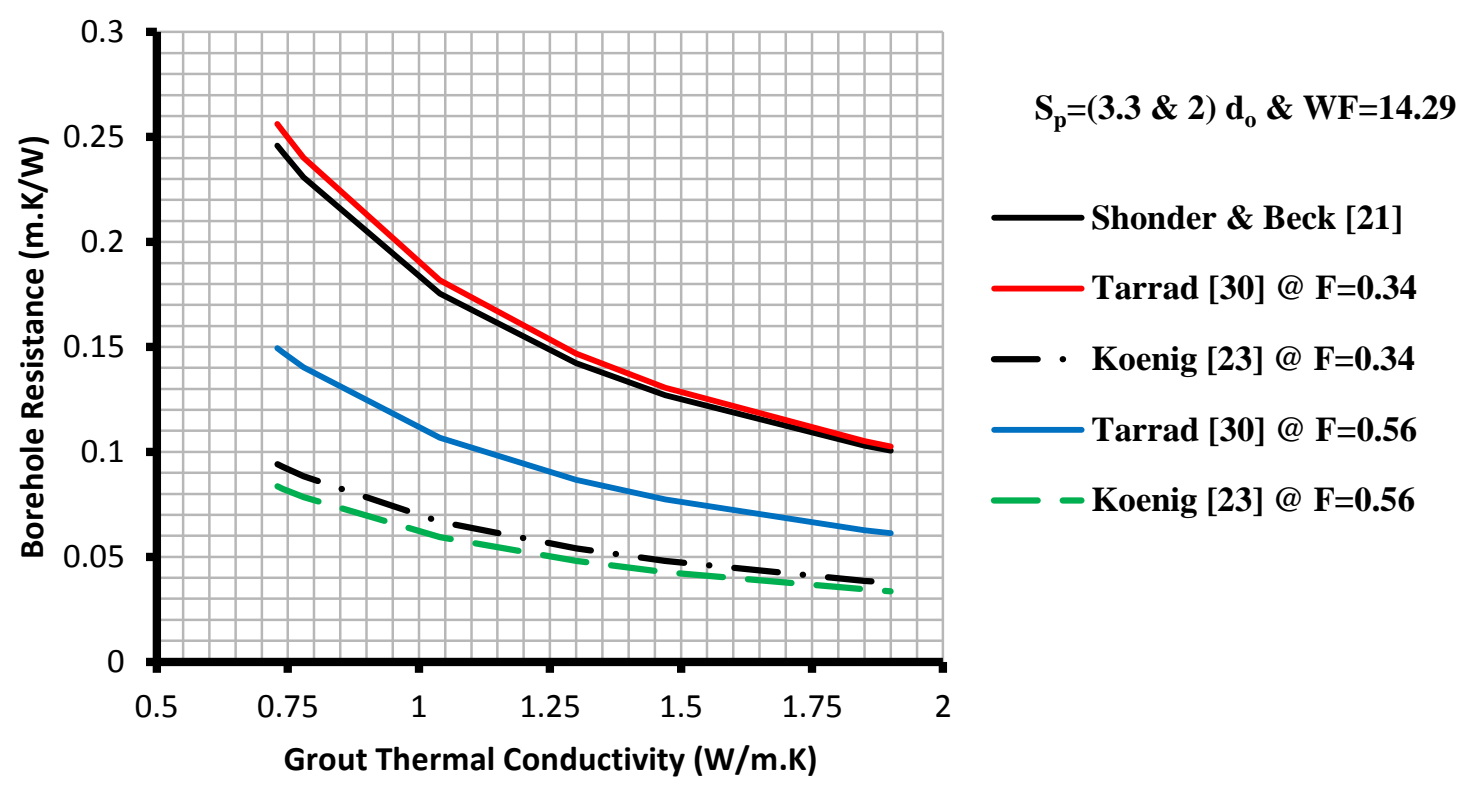

Fig. 8.a. Comparison at $S_{p} / d_{0}=3.3 \& 2, W F=14.29$ at $D_{B}=75 \mathrm{~mm}$ for double U-tubes, $G 2$

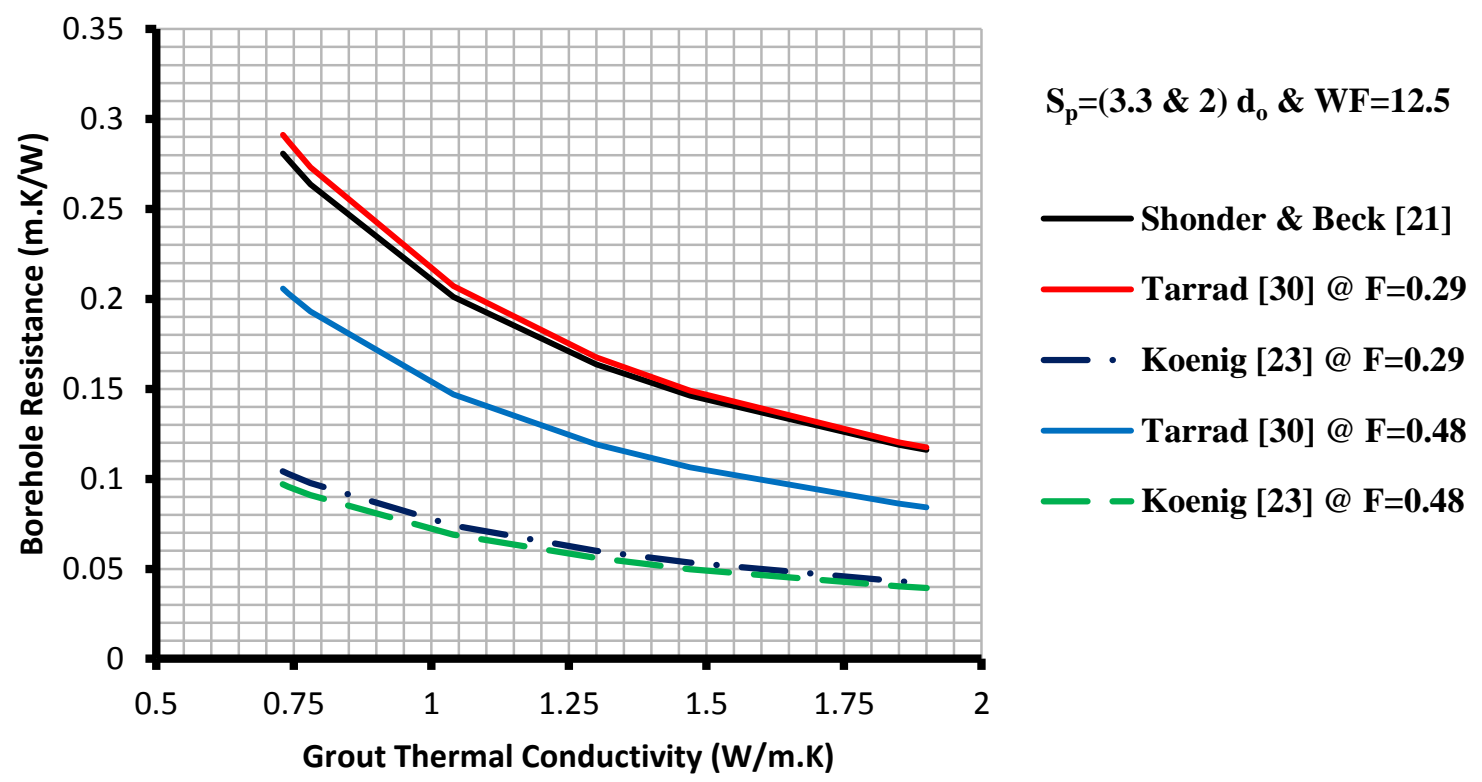

Fig. 8.b. Comparison at $S_{p} / d_{0}=3.3 \& 2, W F=12.5$ at $D_{B}=65 \mathrm{~mm}$ for double U-tubes, $G 1$

Fig. 8. Comparison of borehole thermal resistance of different geometries at a variety of geometry and configuration factors predicted by several correlations 
The configuration factor of the heat exchangers is expressed in terms of the U-tube spacing and borehole size by:

$$
F=\frac{s_{p}}{D_{B}}
$$

The higher the configuration factor is, the closer the tubes to the borehole wall and vice versa. Hence, the heat transfer rate is expected to be higher for the higher configuration factor $(F)$ of the heat exchanger configuration for a fixed borehole size. This is due to minimizing the grout layer that surrounds the tubes with $(F)$ increase, and in turn, it maximizes the heat transfer rate and minimizes the borehole thermal resistance.

The correlation of Shonder and Beck [21] didn't show any interaction with the U-tube spacing for both geometry configurations (G1) and (G2); their formula in Eq. (17) is independent of the tube spacing. The analytical model built by Koenig [23] showed a slight response to the tube spacing for both of the considered configurations, Fig. 8. All of the examined correlations showed a similar data trend for the thermal resistance of all arrangements regardless of the configuration factor. The results dictate that the thermal resistance is inversely proportional to the grout thermal conductivity for all examined geometries. Tarrad [30] model exhibited close numerical values of the borehole thermal resistance to those of Shonder and Beck [21] ones at low $(F)$ factors of (0.29) and (0.34) for both geometries (G1) and (G2), respectively.

The borehole thermal resistance predictions of Koenig [23] correlation for both geometries were much lower than those of Tarrad [30] and Shonder and Beck [21]. This prediction will be reflected in the borehole depth. Hence Koenig [23] model predicts shorter depths than other models. The predicted borehole thermal resistance for G1 by Koenig [23] at $(F)$ of $(0.29)$ was lower than those of Tarrad [30] and Shonder and Beck [21] estimations by (64) \%. It was lower than that predicted by the Tarrad [30] model at $(F)$ of $(0.48)$ by (54) \% for the (G1) configuration. Koenig [23] revealed lower thermal resistance than Tarrad [30] and Shonder and Beck [21] correlations by (63-67) \% at $(F)$ of $(0.34)$ for (G2) configuration. It was lower than that predicted by the Tarrad [30] relation at $(F)$ of $(0.56)$ by $(45)$ $\%$.

\subsection{Borehole Depth}

Garbai and Méhes [15] stated that the ground thermal conductivity approaches a steady-state value of $(0.05) \mathrm{m} . \mathrm{K} / \mathrm{W}$ after a one-year continuous operation. This value was used to estimate the total thermal resistance of the single and double $\mathrm{U}$-tube borehole configurations, hence:

$$
R_{t}=R_{B}+R_{S}
$$

The temperature in the ground below (6) $\mathrm{m}$ is roughly equal to the mean annular air temperature at that altitude. It is at the range of $(10-16)^{\circ} \mathrm{C}$. Seasonal variation decreases with depth and disappears below (7 to 12) $\mathrm{m}$, Tarrad [34]. The objective is to estimate the depth of the borehole as predicted by various correlations from:

$$
\begin{aligned}
& q_{l}=\frac{\Delta T_{m}}{R_{t}} \\
& H_{B}=\frac{\dot{Q}_{\text {cond }}}{q_{l}} \\
& \Delta T_{m}=T_{\text {fluid }, m}-T_{S}
\end{aligned}
$$

A mean temperature difference $\left(\Delta \mathrm{T}_{\mathrm{m}}\right)$ between the refrigerant and ground of (14) ${ }^{\circ} \mathrm{C}$ was utilized. Hence, Fig. 9 is constructed for comparison of different predictions for the borehole depth of geometry (G2) and (G1) with a geometry factor of (3.3). 
Current Approaches in Science and Technology Research Vol. 13 A Brief Review and Evaluation of Available 1-Dimensional Models for the Borehole Thermal Performance Prediction in a Ground-Coupled Heat Pump System

The estimated depths showed an inverse variation with the grout thermal conductivity and approaches a minimum value at (1.9) W/m.K. At high grout thermal conductivity, the predicted depth is getting closer to each other. The depth of the borehole showed a large discrepancy as predicted by the available correlations. The models of Garbai and Méhes [15] and that of Shonder and Beck [21] are quite conservative correlations. They predict much higher depths than those of Koenig [23] and Sharqawy et al. [29].

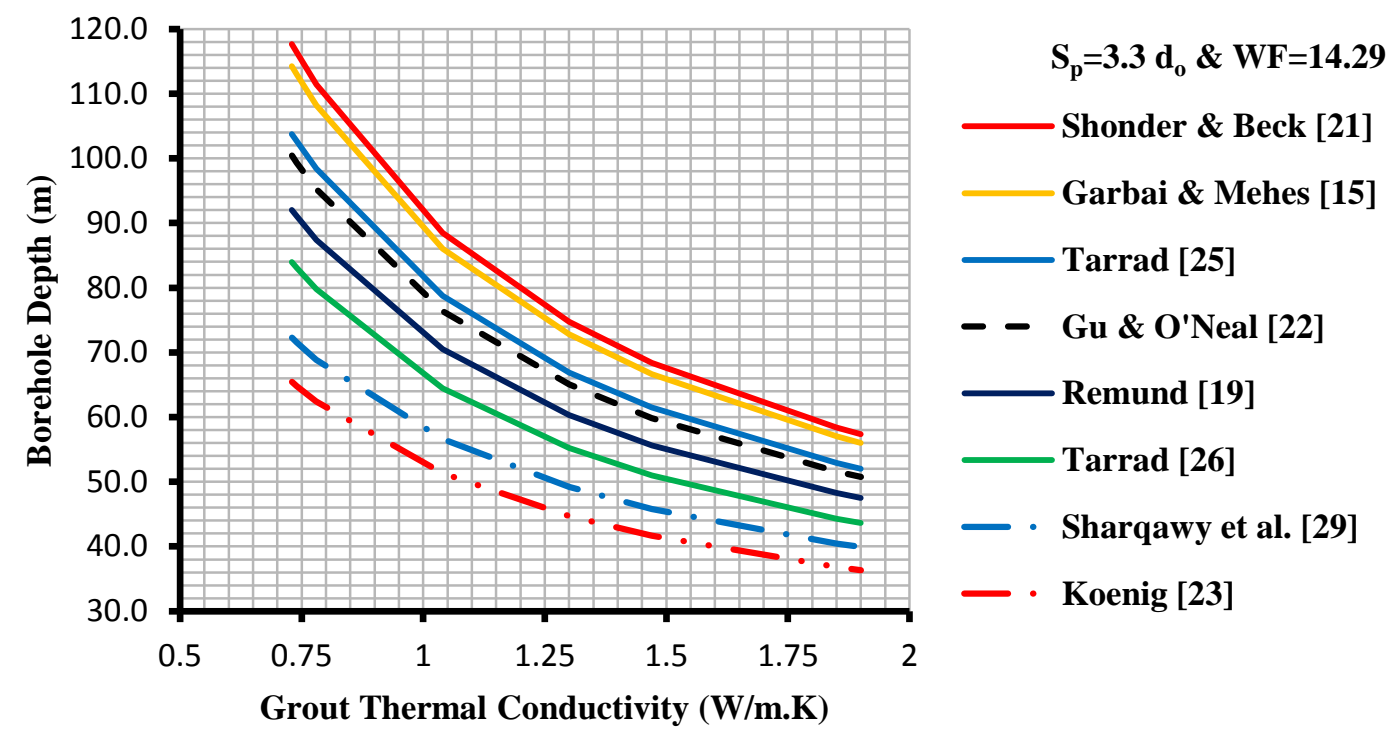

Fig. 9.a. The predicted single loop depth comparison at $S_{p} / d_{0}=3.3, W F=14.29$, $G 2$

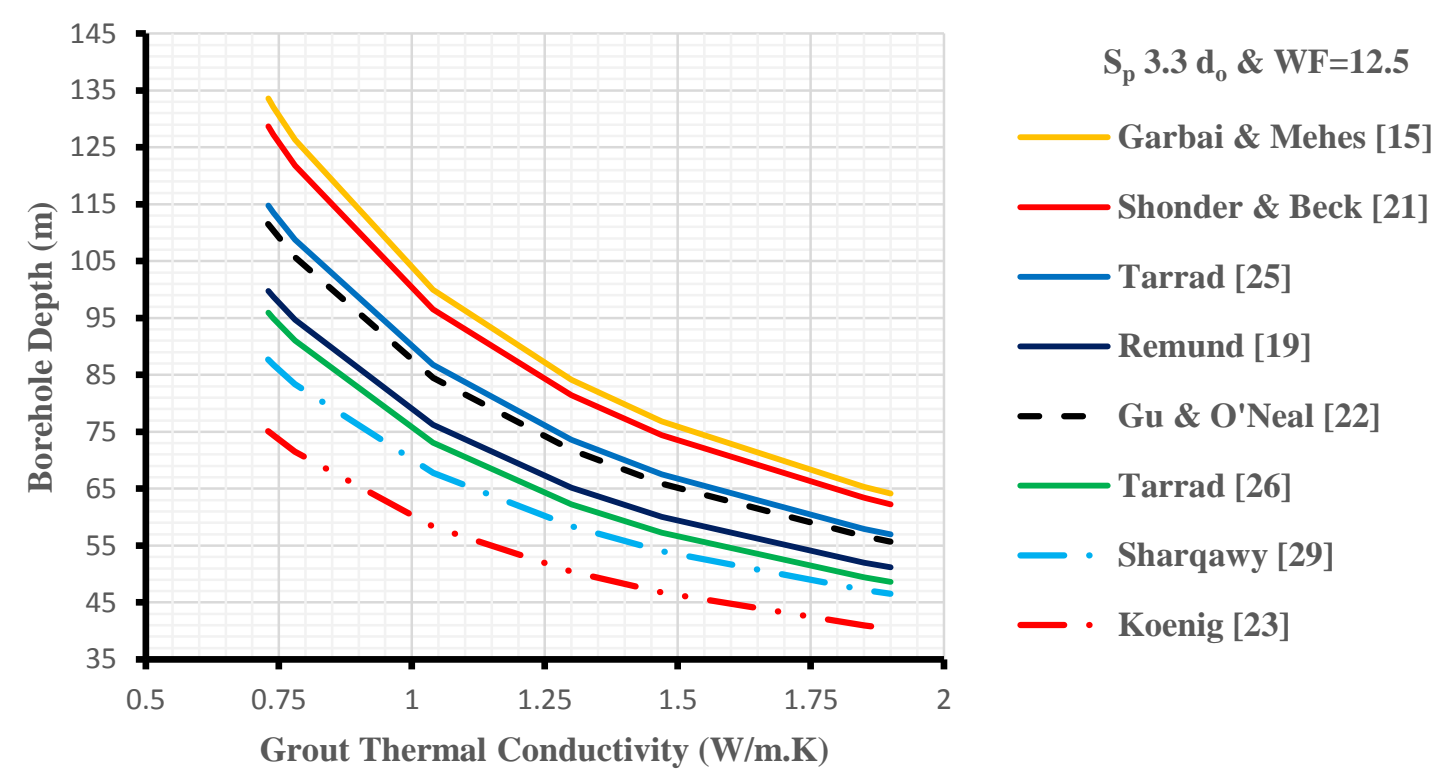

Fig. 9.b. The predicted single loop depth comparison at $S_{\mathrm{p}} / \mathrm{d}_{0}=3.3, \mathrm{WF}=12.5, \mathrm{G} 1$ Fig. 9. The single loop depth comparison at $S_{p} / d_{0}=3.3$ for the examined geometry configurations 
Current Approaches in Science and Technology Research Vol. 13 A Brief Review and Evaluation of Available 1-Dimensional Models for the Borehole Thermal Performance Prediction in a Ground-Coupled Heat Pump System

Table 5 illustrates the deviation percentage of the predicted borehole depths by several correlations as compared to the shortest one that is calculated by Koenig (2015) [23] by the following expression:

$$
\eta_{\text {corr }}=\frac{H_{\text {corr }}-H_{\text {Koenig }}}{H_{\text {corr }}} \times 100
$$

Table 5.a. Predicted depth deviation of various correlations with respect to Koenig [23] one for G2 at geometry factor of (3.3)

\begin{tabular}{|c|c|c|c|c|c|c|c|}
\hline $\begin{array}{l}\mathbf{k}_{\mathrm{g}} \\
(\mathrm{W} / \mathrm{m} \cdot \mathrm{K})\end{array}$ & $\begin{array}{l}{[21]} \\
\eta(\%)\end{array}$ & $\begin{array}{l}{[15]} \\
\eta(\%)\end{array}$ & $\begin{array}{l}{[25]} \\
\eta(\%)\end{array}$ & $\begin{array}{l}{[19]} \\
\eta(\%)\end{array}$ & $\begin{array}{l}{[22]} \\
\eta(\%)\end{array}$ & $\begin{array}{l}{[26]} \\
\eta(\%)\end{array}$ & $\begin{array}{l}{[29]} \\
\eta(\%)\end{array}$ \\
\hline 0.73 & 44.4 & 42.7 & 36.9 & 28.9 & 34.8 & 22.1 & 9.4 \\
\hline 0.74 & 44.3 & 42.6 & 36.9 & 28.8 & 34.8 & 22.0 & 9.4 \\
\hline 0.78 & 44.0 & 42.3 & 36.6 & 28.6 & 34.5 & 21.8 & 9.4 \\
\hline 1.04 & 42.0 & 40.3 & 34.8 & 27.1 & 32.8 & 20.3 & 9.3 \\
\hline 1.3 & 40.1 & 38.6 & 33.2 & 25.9 & 31.2 & 19.1 & 9.1 \\
\hline 1.47 & 39.1 & 37.5 & 32.2 & 25.1 & 30.4 & 18.3 & 9.1 \\
\hline 1.85 & 36.9 & 35.4 & 30.4 & 23.7 & 28.6 & 16.9 & 8.9 \\
\hline 1.9 & 36.6 & 35.1 & 30.1 & 23.5 & 28.4 & 16.7 & 8.9 \\
\hline
\end{tabular}

Table 5.b. Predicted depth deviation of various correlations with respect to Koenig [23] one for G1 at geometry factor of (3.3)

\begin{tabular}{|c|c|c|c|c|c|c|c|}
\hline $\begin{array}{l}\mathbf{k}_{\mathbf{g}} \\
(\mathrm{W} / \mathrm{m} \cdot \mathrm{K})\end{array}$ & $\begin{array}{l}{[15]} \\
\eta(\%)\end{array}$ & $\begin{array}{l}{[21]} \\
\eta(\%)\end{array}$ & $\begin{array}{l}{[25]} \\
\eta(\%)\end{array}$ & $\begin{array}{l}{[22]} \\
\eta(\%)\end{array}$ & $\begin{array}{l}{[19]} \\
\eta(\%)\end{array}$ & $\begin{array}{l}{[26]} \\
\eta(\%)\end{array}$ & $\begin{array}{l}{[29]} \\
\eta(\%)\end{array}$ \\
\hline 0.73 & 43.8 & 41.6 & 34.6 & 32.7 & 24.7 & 21.7 & 14.3 \\
\hline 0.74 & 43.7 & 41.6 & 34.5 & 32.6 & 24.7 & 21.7 & 14.3 \\
\hline 0.78 & 43.4 & 41.3 & 34.3 & 32.4 & 24.5 & 21.5 & 14.3 \\
\hline 1.04 & 41.7 & 39.6 & 32.8 & 31.0 & 23.5 & 20.2 & 13.9 \\
\hline 1.3 & 40.1 & 38.1 & 31.5 & 29.8 & 22.7 & 19.0 & 13.7 \\
\hline 1.47 & 39.2 & 37.2 & 30.8 & 29.1 & 22.2 & 18.4 & 13.5 \\
\hline 1.85 & 37.3 & 35.3 & 29.2 & 27.6 & 21.2 & 17.1 & 13.2 \\
\hline 1.9 & 37.0 & 35.1 & 29.0 & 27.4 & 21.0 & 16.9 & 13.1 \\
\hline
\end{tabular}

For the (G2) geometry configuration, the Shonder and Beck [21] model predicted the higher deviation, it fell in the range of (37-44) \% whereas, the Sharqawy correlation predicted the closer depth to Koenig [23] one with a deviation of (9) \%. For the smaller heat exchanger (G1), Garbai and Méhes exhibited a higher deviation of (37-44) \% and Sharqawy et al. [29] predicted a deviation of (13-14) \%. The other examined correlations revealed a range of deviations bounded by the zone of maximum and minimum predictions.

Fig. 10 illustrates a comparison for the predicted borehole depth of the double U-tube for the examined geometries at $\left(\mathrm{S}_{\mathrm{p}} / \mathrm{d}_{\mathrm{o}}\right)$ of (3.3). The trend of data showed a similar fashion of depth variation with thermal conductivity of filling, it increases as the latter is reduced and approaches a maximum at (0.73) W/m.K. The Shonder and Beck [21] correlation predicted the higher depth among other examined ones, it is a conservative prediction since it didn't take the effect of tube spacing and heat transfer reduction due to the presence of the other tubes in the borehole. Koenig [23] analytical model predicted lower depths and Tarrad [30] showed a mid-way depth as compared to other investigators. 
Current Approaches in Science and Technology Research Vol. 13 A Brief Review and Evaluation of Available 1-Dimensional Models for the Borehole Thermal Performance Prediction in a Ground-Coupled Heat Pump System

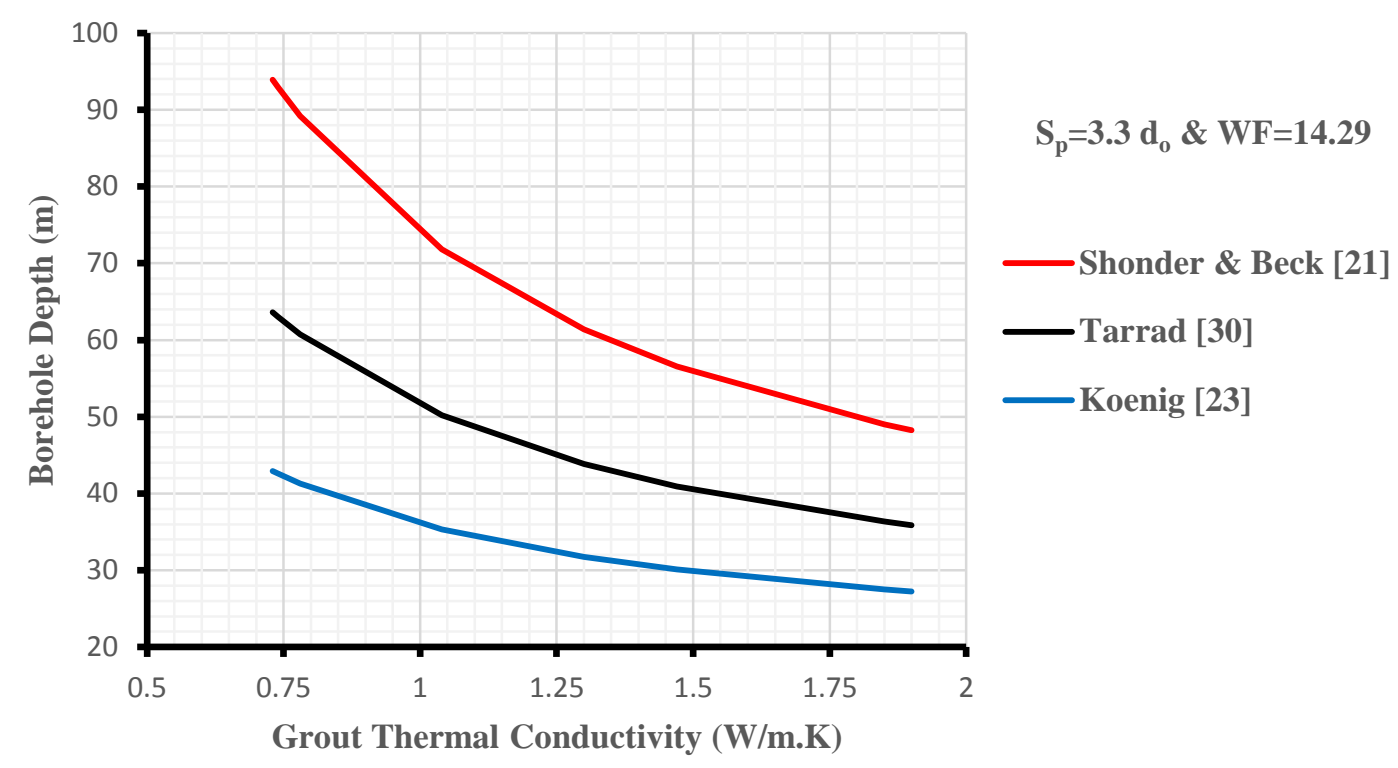

Fig. 10.a. The predicted two-loops depth comparison at $S_{p} / d_{0}=3.3, W F=14.29$, G2

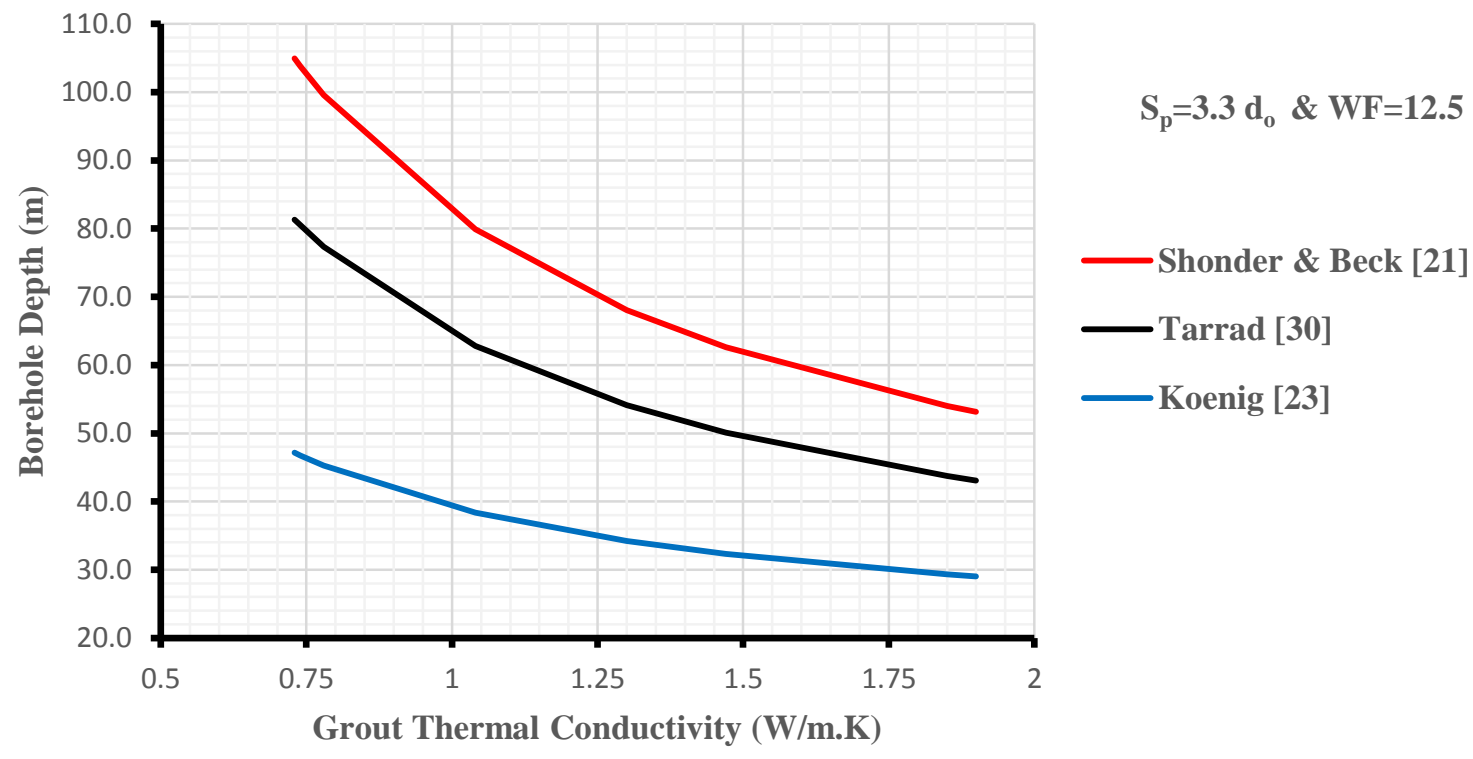

Fig. 10.b. The predicted two-loops depth comparison at $S_{\mathrm{p}} / \mathrm{d}_{0}=3.3, \mathrm{WF}=12.5, \mathrm{G} 1$ Fig. 10. The two-loops depth comparison at $S_{p} / d_{0}=3.3$ for the examined geometry configurations

Fig. 11 depicts a comparison of the borehole depth between the single and two-loops heat exchangers for (G1) and (G2). 
Current Approaches in Science and Technology Research Vol. 13 A Brief Review and Evaluation of Available 1-Dimensional Models for the Borehole Thermal Performance Prediction in a Ground-Coupled Heat Pump System

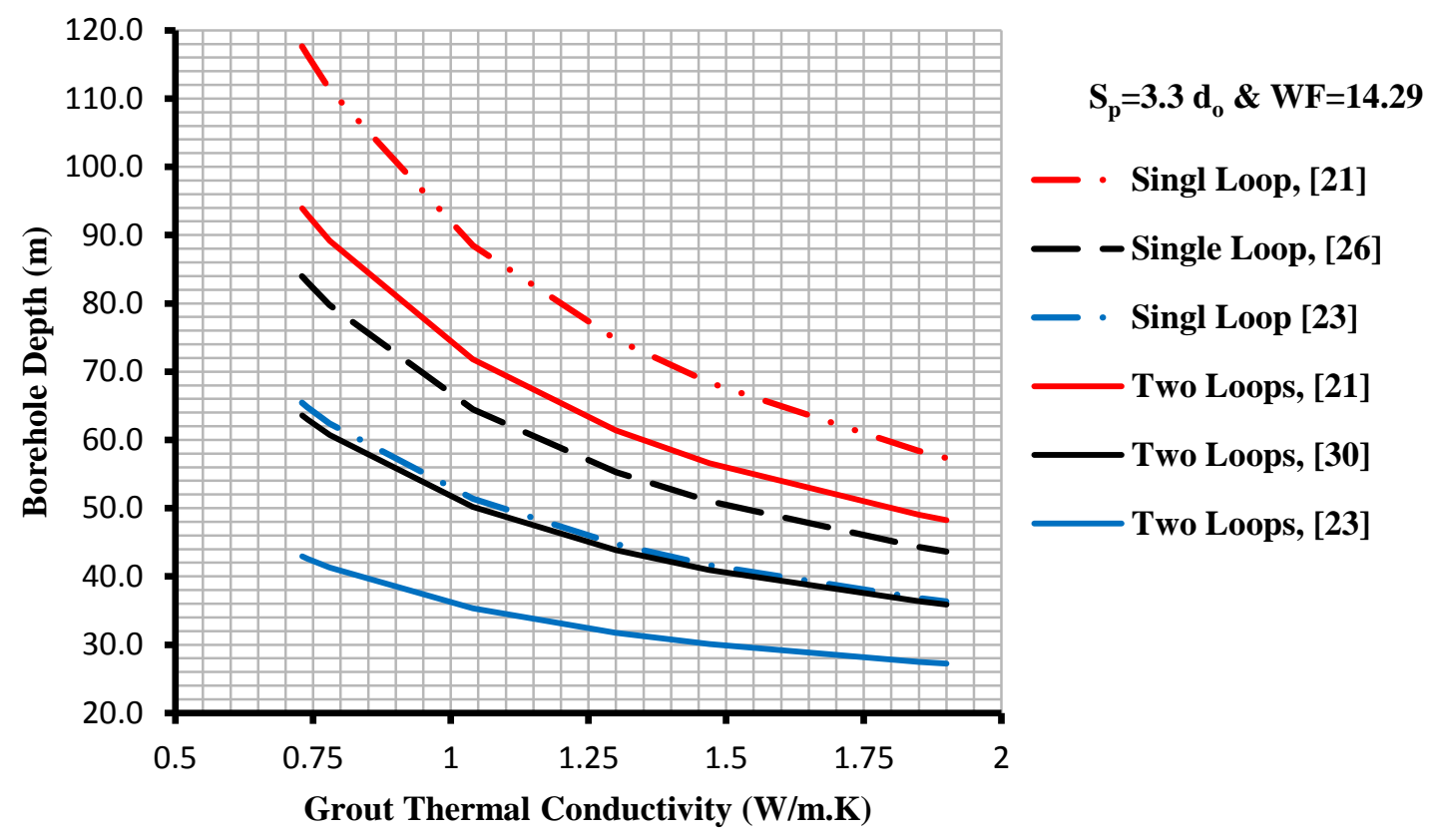

Fig. 11.a. A comparison of borehole depth at $S_{p} / d_{0}=3.3, G 2$

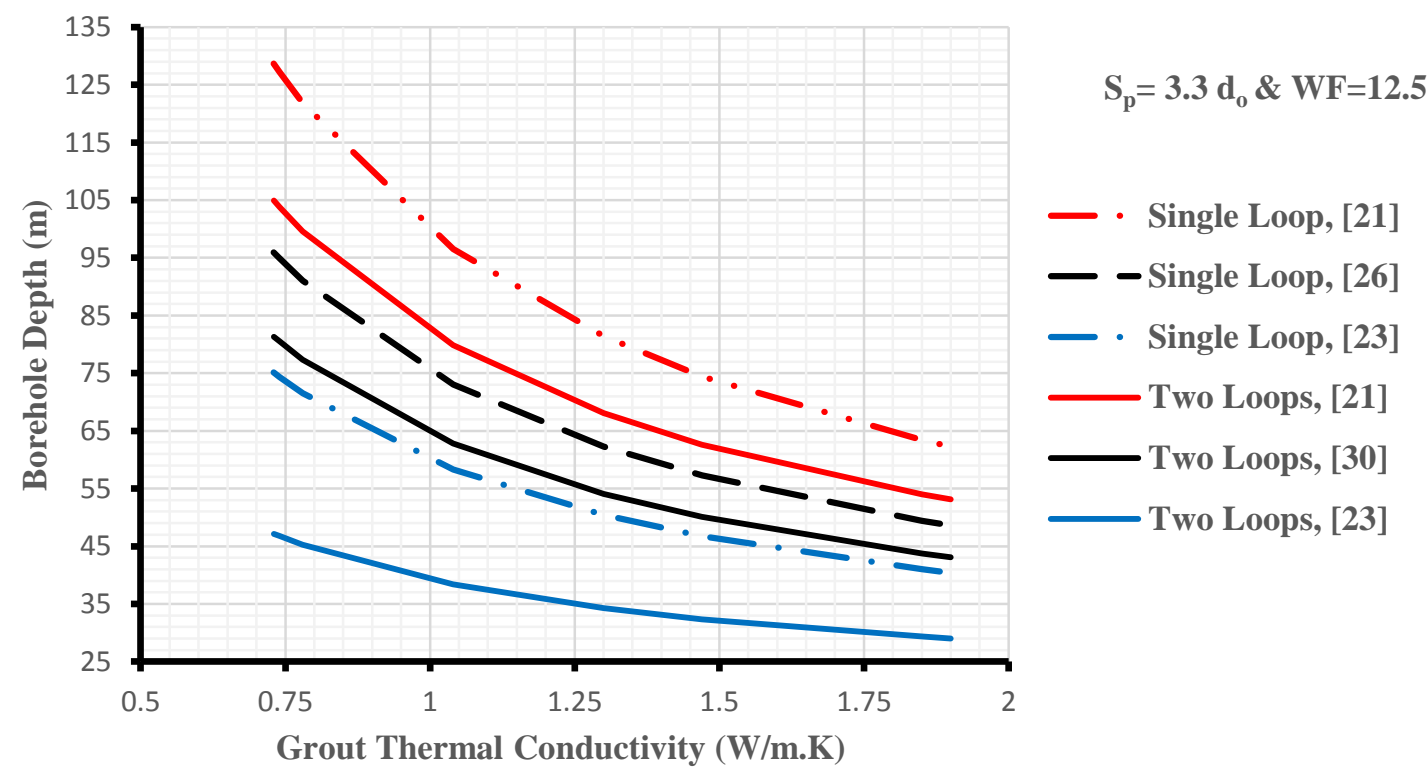

Fig. 11.b. A comparison of borehole depth at $S_{p} / d_{0}=3.3, G 1$

Fig. 11. The comparison of predicted depths between the single and two-loops at $S_{p} / d_{0}=3.3$

All of the examined correlations exhibited a similar data trend. The depth of the two-loops heat exchangers is usually lower than those of the single loop for both (G1) and (G2) geometries. The curves of the single and two-loops are getting closer to each other as the grout thermal conductivity increases. This result dictates that for high grout thermal conductivity, the existence of the second 
Current Approaches in Science and Technology Research Vol. 13 A Brief Review and Evaluation of Available 1-Dimensional Models for the Borehole Thermal Performance Prediction in a Ground-Coupled Heat Pump System

loop doesn't add much enhancement of heat transfer compared with the single loop heat exchanger. The single loop depth increase percentage is defined in terms of the two-loop heat exchanger by:

$$
\xi_{S}=\frac{H_{S}-H_{T}}{H_{S}}
$$

Table 6 shows that the depth of a single loop was bigger than that of the two-loop heat exchanger for both geometries, the higher was noticed at low grout thermal conductivity of $(0.73) \mathrm{W} / \mathrm{m} . \mathrm{K}$ and the opposite at (1.9) W/m.K thermal conductivity.

Table 6. The depth increase percentage of the single to the two-loop heat exchanger

\begin{tabular}{|c|c|c|c|c|}
\hline Geo. & $\begin{array}{l}\mathbf{k}_{\mathrm{g}} \\
(\mathrm{W} / \mathrm{m} \cdot \mathrm{K})\end{array}$ & $\begin{array}{l}\text { Shonder \& Beck [21] } \\
\xi_{s}(\%)\end{array}$ & $\begin{array}{l}\text { Tarrad }[26,30] \\
\xi_{s}(\%)\end{array}$ & $\begin{array}{l}\text { Koenig [23] } \\
\xi_{s}(\%)\end{array}$ \\
\hline \multirow[t]{2}{*}{ G2 } & 0.73 & 20 & 24 & 34 \\
\hline & 1.9 & 16 & 18 & 25 \\
\hline \multirow[t]{2}{*}{ G1 } & 0.73 & 19 & 16 & 37 \\
\hline & 1.9 & 15 & 12 & 28 \\
\hline
\end{tabular}

\section{CONCLUSION}

The present work showed a wide scatter for the thermal parameters of the ground heat exchanger predictions as follows:

\subsection{Two-Loops}

The Koenig [23] and Shonder and Beck [21] models predicted the minimum and maximum borehole depths, respectively, for the examined operating conditions. For (G1) configuration, Shonder and Beck [21] and Tarrad [30] models predicted borehole depths in the range of (1.83-2.21) and (1.481.73) times those of Koenig assessments, respectively for the examined range of grout thermal conductivity. On the other hand, the respective values for the (G2) configuration fell in the field of (1.78-2.2) and (1.33-1.46) times those of Koenig [23] predicted depths for the Shonder and Beck [21] and Tarrad [30] models, respectively.

\subsection{Single-Loop}

The deviation of the predicted borehole depth values was in the range of $(9-44) \%$ as compared to the minimum estimated depths by Koenig [23]. Shonder and Beck [21] and Garbai and Méhes [15] exhibited higher depths than those of the Koenig model by $(35-44) \%$ for both examined configurations. The Shonder and Beck [21] and Tarrad [25] models didn't show any dependence on the geometry factor $\left(\mathrm{S}_{\mathrm{p}} / \mathrm{d}_{\mathrm{o}}\right)$ and, to less extent, the Remund [19] correlation. The single loop borehole depth revealed higher values than that of the double U-tube heat exchanger, the increased percentage $\left(\xi_{s}\right)$ fell in the range of $(15-20) \%,(12-24) \%$ and $(28-34) \%$ as predicted by Shonder and Beck [21], Tarrad [30], and Koenig [23] models, respectively for the examined range of grout thermal conductivity.

\subsection{Geometry Factor}

It has been proved that the geometry factor $\left(S_{p} / d_{0}\right)$ is an essential factor in the estimation of the borehole thermal performance by the considered investigators in the present work. Increasing the geometry factor minimizes the borehole thermal resistance and reduces the borehole depth for fixed borehole diameter. A typical comparison for (G2) showed that at grout thermal conductivity of (1.3) $\mathrm{W} / \mathrm{m} . \mathrm{K}$, the values at $\left(\mathrm{S}_{\mathrm{p}} / \mathrm{d}_{\mathrm{o}}\right)$ of $(2)$ were $(31-43) \%$ higher than those at $\left(\mathrm{S}_{\mathrm{p}} / \mathrm{d}_{0}\right)$ of $(4)$. Similarly, increasing (Sp/do) from (2) to (4) exhibited that the borehole thermal resistance was increased by (1832 ) $\%$. In addition, the increased percentage of the thermal resistances does not show a great dependence on the grout thermal conductivity. 
Current Approaches in Science and Technology Research Vol. 13

A Brief Review and Evaluation of Available 1-Dimensional Models for the Borehole Thermal Performance Prediction in a Ground-Coupled Heat Pump System

\subsection{Grout Thermal Conductivity}

The borehole thermal resistance revealed an increase as the grout thermal conductivity decreases for all examined correlations of the single and double U-tube heat exchangers. The estimated depths showed an inverse variation with the grout thermal conductivity and approaches a minimum value at (1.9) W/m.K. At high grout thermal conductivity, the predicted depths by the examined correlations are getting closer to each other.

More experimental data and theoretical models are needed to assist the thermal design of the twoloops borehole. The borehole depth represents the most economic obstruction of these heat exchangers; hence it should be precisely predicted for economic reasons. The application of the examined correlations and models revealed a wide range of thermal assessment variations. Therefore, they cannot be adopted for a finalized thermal design of the borehole without being supported by experimental data.

\section{ACKNOWLEDGEMENT}

The author expresses his sincere thanks to the administration of the (PAUSE) program of Collège de France and the University of Lorraine for allowing him to continue his research work and the publication of the present work. Thanks, are also due to Professor Pascal Boulet, the director of the Laboratoire Énergies \& Mécanique Théorique et Appliquée (LEMTA) for his unlimited support and encouragement.

\section{COMPETING INTERESTS}

The author has declared that no competing interests exist.

\section{REFERENCES}

1. Bauera D, Heidemann W, Diersch HJG. Transient 3D analysis of borehole heat exchanger modeling, Geothermics. 2011; 40:250-260.

DOI: $10.1016 /$ j.geothermics.2011.08.001

2. Rees SJ, He M. A three-dimensional numerical model of borehole heat exchanger heat transfer and fluid flow, Geothermics. 2013; 46:1-13.

DOI : 10.1016/j.geothermics.2012.10.004

3. Chiasson AD, Spitler JD, Rees SJ, Smith MD. A model for simulating the performance of a shallow pond as a supplemental heat rejecter with closed-loop ground-source heat pump systems, ASHRAE Transactions. 2000; 106(2):107-121.

4. Jalaluddin A, Miyara K, Tsubaki S, Inoue K, Yoshida K. Experimental study of several types of ground heat exchanger using a steel pile foundation, Renewable Energy. 2011; 36:764-771.

5. Zanchini E, Lazzari S, Priarone A. Effects of flow direction and thermal short-circuiting on the performance of small coaxial ground heat exchangers, Renewable Energy. 2010;35:12551265.

DOI: 10.1016/j.renene.2009.11.043

6. Zanchini E, Lazzari S, Priarone A. Improving the thermal performance of coaxial borehole heat exchangers, Energy. 2010; 35:657-666.

DOI: $10.1016 /$ j.energy.2009.10.038

7. Chiasson AD, Spitler JD, Rees SJ, Smith, MD. A Model for Simulating the Performance of a Shallow Pond as a Supplemental Heat Rejecter with Closed-Loop Ground-Source Heat Pump Systems, ASHRAE Transactions, 2000;106(2):107-121.

8. Fisher DE, Rees SJ. Modeling Ground Source Heat Pump Systems in a Building Energy Simulation Program (ENERGYPLUS), Ninth International IBPSA Conference. 2005;311-318. Montréal, Canada. 
Current Approaches in Science and Technology Research Vol. 13 A Brief Review and Evaluation of Available 1-Dimensional Models for the Borehole Thermal Performance Prediction in a Ground-Coupled Heat Pump System

9. Zanchini E, Lazzari S, Priarone A. Effects of Flow Direction and Thermal Short-Circuiting on the Performance of Small Coaxial Ground Heat Exchangers, Renewable Energy. 2010; 35:12551265.

DOI: 10.1016/j.renene.2009.11.043

10. Zanchini E, Lazzari S, Priarone A. Improving the Thermal Performance of Coaxial Borehole Heat Exchangers, Energy. 2010; 35:657-666.

DOI: 10.1016/j.energy.2009.10.038

11. Rees SJ, He M. A Three-Dimensional Numerical Model of Borehole Heat Exchanger Heat Transfer and Fluid Flow, Geothermics. 2013; 46:1-13.

DOI: org/10.1016/j.geothermics.2012.10.004

12. Tarrad AH. A 3-Dimensional Borehole Numerical Modeling for Single and Double U-tube Ground-Coupled Heat Pump, Presented in COMSOL 2020 conference, Grenoble, France; 2020.

13. Tarrad AH. A 3-Dimensional Numerical Thermal Analysis for the Configuration Effect of a Single and Double U-Tube on the Borehole Performance, Presented in the 15th International Conference on Energy Sustainability ES2021, June 16-18, 2021, on-line virtual, USA; 2021.

14. Yavuzturk C, Spitler JD, Rees SJ. A Transient Two-Dimensional Finite Volume Model for the Simulation of Vertical U-Tube Ground Heat Exchangers, ASHRAE Transactions. 1999;105(2):465-474.

15. Garbai L, Méhes S. Heat capacity of vertical ground heat exchangers with single U-tube installation in the function of time, WSEAS Transactions on Heat and Mass Transfer. 2008;3(3):177-186.

16. Bose JE, Parker JD, McQuiston FC. Design/Data manual for closed-loop ground-coupled heat pump systems; American Society of Heating, Refrigeration and Air Conditioning Engineers (ASHRAE): Atlanta; 1985.

17. Fischer RD, Stickford GH. Technical and economic feasibility of horizontal, multiple shallow-well and deep-well ground coupling, ORNUSub/80-78001 3\&06. Oak Ridge, Tenn.: Oak Ridge National Laboratory; 1983.

18. Mei VC, Baxter VD. Performance of a ground coupled heat pump with multiple dissimilar U-tube coils in series, ASHRAE Transactions. 1986; 92(2A):30-42.

19. Remund CP. Borehole thermal resistance: Laboratory and field studies, ASHRAE Transactions. 1999; 105:439-445.

20. Claesson J, Dunand A. Heat Extraction from the Ground by Horizontal Pipes- A mathematical Analysis, Document D1, Swedish Council for Building Research, Stockholm; 1983.

21. Shonder JA, Beck JV. Determining effective soil formation thermal properties from field data using a parameter estimation technique, ASHRAE Transactions. 1999; 105:458-466.

22. Gu Y, O'Neal DL. Development of an Equivalent Diameter Expression for Vertical U-Tubes Used in Ground-Coupled Heat Pumps. ASHRAE Transaction. 1998;104(2):4214,1-9.

23. Koenig AA. Thermal resistance of borehole heat exchangers composed of multiple loops and custom shapes Geothermal Energy. 2015; 3(10):1-14.

DOI: 10.1186/s40517-015-0029-1

24. Tarrad AH. A Borehole Thermal Resistance Correlation for a Single Vertical DX U-Tube in Geothermal Energy Application, American Journal of Environmental Science and Engineering. 2019; 3(4).

DOI: $10.11648 / \mathrm{j}$.ajese.20190304.12

25. Tarrad AH. A Perspective model for borehole thermal resistance prediction of a vertical u-tube in geothermal heat source, Athens Journal of Technology and Engineering. 2020; 7(2):73-92. DOI: 10.30958/ajte.7-2-1

26. Tarrad AH. Development of Analytical Model for a Vertical DX Single U-Tube Ground-Coupled Heat Pump System, Global Journal of Researches in Engineering, J: General Engineering. 2020; 20(3):1-14. DOI: 10.34257/GJREJVOL20IS3PG1

27. Sagia Z, Stegou A, Rakopoulos C. Borehole Resistance and Heat Conduction around Vertical Ground Heat Exchangers, The Open Chemical Engineering Journal. 2012; 6:32-40.

28. Holman JP. Heat Transfer, $10^{\text {th }}$ edition, published by McGraw-Hill, chapter. 2010; 3:83-86. 
29. Sharqawy MH, Mokheimer EM, Badr HM. Effective Pipe-to-Borehole Thermal Resistance for Vertical Ground Heat Exchangers, Geothermics. 2009; 38:271-277.

30. Tarrad AH. Analytical model for thermal assessment of a vertical double u-tube ground-coupled heat pump system operates at steady-state conditions, Presented in the International Conference on Materials \& Energy (ICOME21). Metz-France; 2021.

31. Gaia Geothermal. Ground Loop Design Software, GLD; 2009.

32. Huang X, Ding G, Hu H, Zhu Y, Gao Y, Deng B. Condensation Heat Transfer Characteristics of R410A-oil Mixture in $5 \mathrm{~mm}$ and $4 \mathrm{~mm}$ Outside Diameter Horizontal Microfin Tubes, Experimental Thermal and Fluid Science. 2010; 3(7):845-856.

33. Kim M, Shin J. Condensation Heat transfer of R-22 and R410A in Horizontal Smooth and Micorofin Tubes, Int. J. of Refrigeration. 2005; 28:949-957.

34. Tarrad AH. The Utilization of Renewable Energy Source and Environment Friendly Refrigerants in Cooling Mode, Sustainable Energy. 2019;7(1):6-14.

DOI: $10.12691 /$ rse-7-1-2 
Current Approaches in Science and Technology Research Vol. 13 A Brief Review and Evaluation of Available 1-Dimensional Models for the Borehole Thermal Performance Prediction in a Ground-Coupled Heat Pump System

\section{Biography of author}

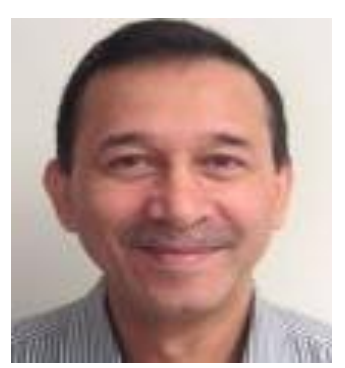

Ali H. Tarrad

Université de Lorraine, CNRS, LEMTA, F-54000 Nancy, France.

Research and Academic Experience: In 1991 he was awarded the (Ph.D.) degree in Mechanical Engineering from HeriotWatt University/United Kingdom. He worked in the industrial field for more than 14 years as a thermal engineering specialist. The work included project management and planning in addition to the thermal design of equipment. These projects covered many topics in the energy sector such as Power Plant Technology, Petroleum Refinery industry, Air Conditioning and Refrigeration Systems, and the Food industry. He worked in the education sector for more than 30 years as a researcher, tutor, and research supervisor in the energy/power division-Mechanical Engineering in the UK, Iraq, Denmark, and France.

Research Area: His field of interest is related to energy management, sustainable energy and waste energy recovery, heat pump technology, refrigeration, and heat transfer.

\section{Number of Published Papers: 60.}

Special Award: 1- Henry Black Memorial Prize in 1991, Heriot-Watt university

2- An official acknowledgment certificate by the Iraqi Ministry of Higher Education and Research Council due to the research activity shown in (2010-2011) academic year.

(C) Copyright (2021): Author(s). The licensee is the publisher (B P International). 